\title{
Financialization and unconventional monetary policy: a financial-network analysis
}

\author{
Chiara Perillo $^{1}$ (D). Stefano Battiston ${ }^{1}$
}

Published online: 15 September 2020

(C) The Author(s) 2020

\begin{abstract}
Over the last decades, both advanced and emerging economies have experienced the emergence of the phenomenon known as financialization, that, until some time ago, was generally considered beneficial for the economy. The 2007-2008 crisis and the severe post-crisis recession called into question the assumptions underlying the positive perception of the role played by financialization in the economy. In particular, the effects of financialization on financial stability and inequality are now widely recognized. A recent debate focused on the effectiveness of unconventional monetary policy tools in transferring their effects on the financial sphere to the economic sphere (e.g., via stimulating the transmission of resources from the banking system to the real economy). Among these unconventional policy measures, Quantitative Easing (QE) has been recently implemented by the European Central Bank (ECB). In this context, two questions deserve more attention in the literature. First, to what extent QE may generate net flows of additional resources to the real economy. Second, to what extent QE may also alter the pattern of intra-financial exposures among financial actors and what are the implications in terms of financialization. Here, we address these two questions by mapping and analyzing the euro area multilayer macro-network of financial exposures among institutional sectors across financial instruments (i.e., loans, bonds, equity, and insurance and pension schemes) and we illustrate our approach on recently available data. We then test the effect of the implementation of ECB's QE on some novel measures of financialization that we derive from the time evolution of the financial linkages in the multilayer macro-network of the euro area.
\end{abstract}

Keywords Financialization · Unconventional monetary policy ·

Quantitative easing · Real economy · Financial stability · Multilayer networks ·

Macro-networks · Financial networks

Chiara Perillo

chiara.perillo@bf.uzh.ch

Extended author information available on the last page of the article. 
JEL Classification E51 - E52 · E58 · E65

\section{Introduction}

Over the last decades, both advanced and emerging economies have experienced the emergence of the phenomenon known as financialization of the economy, meaning, broadly speaking, "more finance, better paid, playing a more pervasive role in economic life" (Turner 2017). ${ }^{1}$ From the 1970 s on, finance grew far faster than the real economy (Haldane et al. 2010), private credit increased more rapidly than the Gross Domestic Product (GDP) (Reinhart and Rogoff 2013), financial trading grew dramatically relative to the underlying real economy flows (Bank for International Settlements (BIS) 2008; 2013), and the financial system became far more complex (Akerlof and Shiller 2015). The dramatic acceleration of finance's growth has been mainly driven by two factors: i) the provision of credit and financial services to the economy, and in particular to households, associated with ii) the striking growth in asset management activities and profits (Greenwood and Scharfstein 2013). The first factor has resulted in the dramatic growth in the private sector leverage (Turner 2017). The second factor has arisen from the fact that, for each unit of financial services consumed by the real economy, many more, and more complex, financial activities were performed (Turner 2017). A large part of these complex activities was intra-financial (D'Errico et al. 2018), meaning that a great portion of the financial system's contracts had as a counterparty another financial institution. As a consequence, a large fraction of the financial system's assets was intra-financial (Allahrakha et al. 2015).

Despite some empirical evidence suggesting that the effect of financialization on the economy depends on country-specific features affecting the finance-growth nexus (such as the country's level of development) (Favara 2003; Dufrénot et al. 2009) ${ }^{2}$, until the 2007-2008 crisis, financialization was generally considered beneficial for the economy (International Monetary Fund (IMF) 2006; Dudley and Hubbard 2004;

\footnotetext{
${ }^{1}$ For a more extensive discussion on the multiple definitions of financialization provided by the existing literature see Section 2.3 .

${ }^{2}$ In particular, in order to shed light on the effect of financial intermediation or development on the real sector, Favara (2003) relaxes the standard assumption of a uniform finance-growth nexus across countries behind the statistical evidence of the well-established positive link between finance and growth, by considering the possibility that the finance-growth nexus varies across nations (Dufrénot et al. 2009). More specifically, by using dynamic specifications allowing for slope heterogeneity across countries in regressions that link financial variables to growth, Favara (2003) provides empirical evidence in contradiction to the vast literature suggesting that finance and growth are positively linked (Dufrénot et al. 2009). In the same line, Dufrénot et al. (2009) consider a model with a factor structure that allows them to determine whether the finance-growth link is due to cross countries dependence and/or whether it characterizes countries with strong heterogeneities. By employing panel data techniques in their regression analysis, Dufrénot et al. (2009) find that financial intermediation is a positive determinant of growth in developed countries, while it acts negatively on the economic growth of developing countries.
} 
Rajan and Zingales 2004). ${ }^{3}$ In particular, first, based on the assumption that the financial sector lends money to firms to finance new capital investment, financial deepening (i.e., the overall size of the formal financial intermediary system relative to economic activity (King and Levine 1992) ${ }^{4}$ ) was considered beneficial to economic growth (Turner 2017). Second, based on the assumption that full risk diversification is always optimal and its beneficial effect always prevails, the increase in financial interactions (mainly due to the intensified intra-financial interactions (Oliver Wyman 2010)) was believed helpful in making the financial system more resilient and less vulnerable to shocks (International Monetary Fund (IMF) 2006). However, in 20072008, the advanced economies suffered the biggest financial crisis since the 1930s, followed by a severe post-crisis recession, shedding light on the misleading assumptions underlying the positive perception of the role played by financialization in the economy. More specifically, first, the standard textbook role of the financial system as intermediary of households' savings for productive investment in the business sector represents only a marginal share of the modern banking system's business (Jordà et al. 2016). Most credit funds the purchase of assets that already exist (Turner 2017) and a large fraction of this credit is intra-financial (Allahrakha et al. 2015). Second, financial links of different nature among institutions have, in principle, an ambiguous effect, since they allow for the diversification of risk, but at the same time enable financial contagion (Allen and Gale 2000; Battiston et al. 2012a). Indeed, the global financial crisis has shown that intra-financial linkages represent a mechanism for the propagation of financial distress and they may lead to the amplification of small shocks (Bardoscia et al. 2015; Visentin et al. 2016). Consequently, intra-financial interconnectedness is nowadays recognized as one of the key elements of potential financial instability or systemic risk (i.e., the risk of the default of a large portion of the financial system) (Battiston et al. 2016a; Roukny et al. 2016). In this regard, a relatively recent stream of literature has found conditions on the propagation of financial contagion such that full diversification or full financial integration is not optimal (Battiston et al. 2012a; Allen et al. 2012; Castiglionesi and Navarro 2008; Wagner 2010; Stiglitz 2010). Last but not least, rising inequality has been a striking feature of most advanced economies over the past 30 years (Jacobs and Mazzucato 2016), and the financialization of the economy, characterized by the financial system's excess wages and profits (Philippon and Reshef 2012), is considered as one of the main drivers for this increase (Turner 2017).

The 2007-2008 crisis was followed by a credit crunch and fixing the financial system, and in particular banks, seemed a top priority for a debt-intensive econ-

\footnotetext{
3 "In the last thirty years, dramatic changes in financial systems around the world amounting, de facto, to a revolution have brought many. . advances. We have come closer to the utopia of finance for all." (Rajan and Zingales 2004) (as referenced by Turner (2017)).

${ }^{4}$ For an extensive discussion on the wide range of indicators employed by the existing literature to measure financial deepening see Section 2.3.
} 
omy (i.e., an economy with large debt contracts outstanding) (Turner 2017). Indeed, a debt-intensive economy relies on the continuous supply of credit, without which many companies would stop investing and in some cases default (Turner 2017). This priority has translated in a complex combination of policies (such as bailouts, macroprudential and unconventional monetary policies ${ }^{5}$ ) aimed at restoring the financial system's stability, market confidence in bank solvency, and the banking system's credit supply (Turner 2017). In other words, the main argument behind the implementation of these policies is the following. An economic policy favoring the banking system, in the end, would benefit the whole economy, for example, via the restoring of the bank lending channel (and, in particular, bank lending activity addressed to the real economy) and the subsequent achievement of central banks' objectives. Among the aforementioned policies, the expanded Asset Purchase Programme (APP), has been recently implemented by the European Central Bank (ECB). This program consists of large-scale asset purchases and encompasses the set of measures commonly known as Quantitative Easing (QE). Indeed, the APP includes all purchase programs under which private and public securities (such as sovereign and corporate bonds, and asset-backed securities) are massively purchased by the Eurosystem in order to address the risk of a protracted period of low inflation (European Central Bank 2017b). In particular, the APP, announced in January 2015, encompasses the existing i) third Covered Bond Purchase Programme (CBPP3) (started on 20 October 2014), and ii) Asset-Backed Securities Purchase Programme (ABSPP) (started on 21 November 2014). Further, it combines them with the new iii) Public Sector Purchase Programme (PSPP) (started on 9 March 2015), and iv) Corporate Sector Purchase Programme (CSPP) (started on 8 June 2016) (Gambetti and Musso 2017). Monthly net purchases of public and private sector securities amounted to 60, 80, 30, and 15 billion euros on average from March 2015 to December 2018. ${ }^{6}$ More specifically, the large majority of these purchases has been made under the PSPP, which consists of the massive net acquisition of public sector securities ${ }^{7}$ by the Eurosystem from the banking system on the secondary market against central bank money (European Central Bank 2015).

The large-scale purchases imply an increase in the prices of the purchased assets and an injection of money in the banking system. As a consequence, a wide range of interest rates fall and loans become cheaper (European Central Bank 2017d). Therefore, the financial stability of the banking system should benefit both from the newly created bank reserves and the increase in the value of the purchased bonds. Indeed,

\footnotetext{
${ }^{5}$ Unconventional monetary policy consists of those measures that directly target the cost and availability of external finance to banks, households, and non-financial companies, when conventional tools can no longer achieve the central banks' objectives (Smaghi 2009).

${ }^{6}$ More specifically, from March 2015 until March 2016 and from April 2017 until December 2017, the average monthly pace was $€ 60$ billion. From April 2016 until March 2017, the average monthly pace was $€ 80$ billion. From January 2018, the net purchases have been reduced to the monthly pace of $€ 30$ billion, while from October 2018, to the monthly pace of $15 €$ billion (European Central Bank 2017b).

${ }^{7}$ The public sector securities that have been purchased within the PSPP include i) nominal and inflationlinked central government bonds and ii) bonds issued by recognised agencies, regional and local governments, international organizations, and multilateral development banks located in the euro area (European Central Bank 2017b).
} 
banks with significant holdings of these bonds should experience some windfall gains, resulting in an indirect bank recapitalization (Acharya et al. 2018). ${ }^{8}$ As a consequence, on the credit supply side, since the injection of money together with "lower bank run risk frees up liquidity for lending” (Acharya et al. 2018), QE may stimulate bank lending activity. On the credit demand side, due to lower loan rates, firms and households may be able to borrow more and spend less to repay their debts. If so, consumption and investment may receive a boost and support economic growth and job creation and, as prices rise, the ECB achieves an inflation rate below, but close to, $2 \%$ over the medium term (European Central Bank 2017d). Consequently, QE may restore the banking system's financial stability and the market confidence in bank solvency, as well as generate an increase in bank credit to the real economy and all the subsequent aforementioned chain of effects. However, QE does not necessarily imply that the banking system is going actually to exploit its regained lending capacity and increase the credit supply to the real economy. Consequently, QE does not necessarily imply that the potential positive developments concerning the financial sphere are going to be transferred to the economic sphere. In fact, on the one hand, businesses and households may be not willing or able to borrow more from banks. Indeed, they may be "either in the process of repairing their balance sheets or are still suffering from the after-effect of debt trauma". " If so, QE would not produce significant changes in their borrowing behavior. On the other hand, banks may either decide to i) keep the liquidity in the form of reserves at the Eurosystem (with low or even negative remuneration rate, but risk-free), or ii) invest it in the stock market (the returns of which may be more appealing compared to the decreased returns of the securities purchased under the APP). Further, they may as well decide to iii) increase the intra-financial interactions via different financial instruments (e.g., increasing intra-financial loan, bond, and equity contracts). This may lead to the alteration of the pattern of intra-financial exposures among financial actors (including banks, investment funds, insurance corporations, pension funds, and other financial institutions), with potential implications in terms of financialization and, thus, in terms of financial stability and inequality.

Despite there having been some efforts in the recent economic literature to investigate the effects of unconventional monetary measures, ${ }^{10}$ the exploration of the implications of the recently implemented APP both in terms of stimulation of the

\footnotetext{
${ }^{8}$ In particular, Acharya et al. (2018) provide empirical evidence that banks with significant holdings of government bonds realized substantial windfall gains after unconventional monetary policy's announcements and this improved their equity capitalization and liquidity. This empirical evidence is especially associated with the popular "whatever-it-takes speech", delivered by the President of the European Central Bank Mario Draghi on July 26th, 2012.

${ }^{9}$ See "Why US Quantitative Easing “worked" better than other QEs" by Richard Koo, Financial Times, July 19, 2016.

${ }^{10}$ In particular, among others, Acharya et al. (2017), Crosignani and Carpinelli (2016), Daetz et al. (2016), Krishnamurthy et al. (2017), Grosse-Rueschkamp et al. (2017), and Acharya et al. (2018) focus on the European setting, while, Agarwal et al. (2017), Rodnyansky and Darmouni (2017), Chakraborty and Goldstein (2017), and Di Maggio et al. (2016) focus on the U.S. framework. Further, Joyce et al. (2011) analyze the U.K. context, while Gambacorta et al. (2014), Borio and Zabai (2018), and Lima et al. (2016) analyze the cross-country implications of QE.
} 
real economy and financialization from a complex-network perspective would be of great importance. In particular, a financial network analysis would enable the consideration of the complex intra-financial interconnections and their potential effects on financial stability, neglected by traditional tools. Network theory has been widely applied in the financial domain to provide useful insights and predictions on the interconnectivity of the financial system and on the propagation of shocks, especially with reference to the banking sector (Eisenberg and Noe 2001; Elsinger et al. 2006; Battiston et al. 2012b; Roukny et al. 2013; Battiston et al. 2016b). However, less attention has been devoted to the study of the interplay between monetary policy and the network of financial exposures able to take into account of both the interactions between the real and the financial sector and intra-financial interconnectedness (Perillo and Battiston 2017; 2018). In particular, in light of the above context, two fundamental questions deserve more attention in the literature:

1. To what extent does QE generate net flows of additional resources to the real economy?

2. To what extent does QE alter the pattern of intra-financial exposures among financial actors and what are the implications in terms of financialization?

Here, we address these two questions by taking a financial-network perspective to unconventional monetary policy. More specifically, first, building on Perillo and Battiston (2018) we map the macro-network of financial exposures among the different institutional sectors operating in the euro area (i.e., Monetary Financial Institutions, Other Financial Institutions, Non-MMF Investment Funds, Insurance Corporations and Pension Funds, Households, Non-Financial Corporations, and General Governments) and the rest of the world. In particular, we regard this macro-network as a multilayer weighted network in which the multiple layers correspond to different financial instruments (e.g., loans, bonds, equity, etc.). Second, we illustrate our approach on recently available data with a particular focus on i) loan and deposit, ii) private and public security, iii) share and other equity, and iv) insurance and pension scheme contracts through which the aforementioned institutional sectors are tied to each other. Third, we perform both a layer-by-layer analysis and a comprehensive analysis of the euro area economy as a multilayer macro-network. The latter allows us to estimate the direct and indirect financial interdependencies existing between the banking sector and both the real and the financial sectors via the different financial instruments considered together, prior to and after the implementation of QE. Further, this analysis provides us with a map of the potential channels through which distress may propagate as a consequence of shocks of different nature that we identify both prior to and after the implementation of the policy under analysis. Fourth, we compute some network statistics (i.e., a generalization of the weighted and nonweighted version of the degree, closeness, and betweenness centrality measures, and the Katz centrality measure) and estimate the generalized DebtRank financial contagion model, in order to provide a comparison in terms of nodes' centrality and vulnerability prior to and after the implementation of QE. Fifth, building on the multilayer macro-network analysis of the euro area, we propose some novel indicators able to capture i) the transmission of resources to the real economy through the increase of the interactions between the financial sector and the real sector, and ii) the level 
of financialization of the euro area through the increase of the intra-financial interactions, via loans and deposits, securities, and equity, since the implementation of QE. This approach represents a tangible step ahead in the comprehensive analysis of the effects of unconventional monetary policy, which until now mainly involved macroeconomic implications or the impact on financial markets, neglecting network effects and their interplay with financialization.

The remainder of this paper is organized as follows. In Section 2, we introduce the methodology employed to map and analyze the multilayer macro-network of financial exposures among the different institutional sectors operating in the euro area and the rest of the world. Further, we propose some novel measures of financialization able to capture the importance of the role played by the financial system in the euro area economy. In Section 3, we illustrate the employed data and sources. In Section 4, we provide and discuss the exploratory results both from a static and a dynamic perspective. Finally, Section 5 concludes the paper.

\section{Methodology}

\subsection{Institutional sectors}

Following the standards of the European System of National and Regional Accounts (ESA2010), we consider the euro area economy as an open economy composed by four macro sectors: i) the financial sector, ii) the non-financial private sector (or the real sector), iii) the non-financial public sector, and iv) the rest of the world. The financial sector comprises i) Monetary Financial Institutions (MFI), ii) Other Financial Institutions (OFI), iii) Investment Funds other than money market funds (Non-MMF IF), and iv) Insurance Corporations and Pension Funds (IC\&PF). More specifically, the institutional sector Monetary Financial Institutions consists of those financial institutions that form the money-issuing sector of the euro area (European Central Bank 2006). Indeed, MFI are broadly equivalent to banks and include the i) Eurosystem ${ }^{11}$, ii) resident credit institutions, and iii) all other resident financial institutions the main business of which consists in collecting deposits and close substitutes for deposits from entities other than MFI, granting credit, and investing in securities (such as money market funds ${ }^{12}$ ) (European Central Bank 2006). Other Financial Institutions are non-bank financial institutions other than investment funds, insurance corporations, and pension funds. In particular, they may be defined as corporations or quasi-corporations engaged mainly in financial intermediation by

\footnotetext{
${ }^{11}$ The Eurosystem includes the European Central Bank (ECB) and the National Central Banks (NCB) of the nineteen countries belonging to the European Monetary Union (EMU). The European Union's Member States that have adopted the euro in stage three of EMU are Austria, Belgium, Cyprus, Estonia, Finland, France, Germany, Greece, Ireland, Italy, Latvia, Lithuania, Luxembourg, Malta, Netherlands, Portugal, Slovakia, Slovenia, Spain.

${ }^{12}$ Money market funds are investment companies with low-risk and low-return portfolios, which usually include short-term securities, bank deposits, and money market instruments (European Central Bank 2006).
} 
incurring liabilities in forms other than currency, deposits and close substitutes for deposits from institutional entities other than MFI (European Central Bank 2017a). Investment Funds other than money market funds include all collective investment companies, except for money market funds, issuing investment fund shares or units to invest the capital raised from the public in long-term financial assets and nonfinancial assets (Bank of Latvia 2018). Insurance Corporations and Pension Funds include all financial corporations and quasi-corporations that are essentially engaged in financial intermediation as a consequence of i) the pooling of risks mainly in the form of direct insurance or reinsurance in the case of insurance corporations, and ii) the pooling of social risks and needs of the insured person (social insurance) in the case of pension funds (European Central Bank 2017a). According to European Commission (2017), the aforementioned institutional sectors belong to the category of financial corporations, defined as all private and public entities engaged in financial intermediation. The non-financial private sector includes i) Households and nonprofit institutions serving households, ${ }^{13}$ such as charities and trade unions $(\mathrm{HH})$, and ii) Non-Financial Corporations (NFC). More specifically, the household sector covers individuals or groups of individuals as consumers, but also as entrepreneurs (i.e., sole proprietorships and partnerships) (European Central Bank 2017a). The institutional sector Non-Financial Corporations comprises all corporate enterprises that produce goods or provide non-financial services to the market (European Commission 2017). The non-financial public sector consists of General Governments $(G G)$, i.e., central, state (regional) and local governments, and social security funds (European Commission 2017). Lastly, the sector Rest of the World (RW) includes the financial sectors, the real sectors, and the non-financial public sectors, at an aggregate level, operating in non-euro area countries, with an outstanding exposure to the institutional sectors operating in the euro area countries.

\subsection{The multilayer macro-network of financial exposures}

The global financial crisis has called into question the adequacy of traditional tools in predicting and explaining periods of financial distress, due to their inability to account for the potential effects of complex intra-financial interconnections on financial stability. In light of this, it has become clear that the economy should be regarded as a financial network, where, at the highest level of granularity, nodes are the institutions or individuals operating within the different institutional sectors that make up the economy, while links may represent the financial contracts outstanding among them. This network may be defined as the micro-network of financial exposures. Since financial contracts among institutions or individuals occur through different kinds of financial instruments (e.g., loan and deposit, bond, and equity contracts),

\footnotetext{
${ }^{13}$ It is worth mentioning that, although according to ESA2010, non-profit institutions serving households are a separate institutional sector, in the European accounts they are reported together with households (European Central Bank 2017a; European Commission 2017). For this reason and since their economic weight is relatively limited (European Commission 2017), we decided to group them with households.
} 
this micro-network of financial exposures may be regarded as a multilayer network of financial exposures, where layers correspond to different financial instruments. Despite the fact that the multilayer micro-network would be the ideal way of regarding the economy, granular data on financial exposures are not always available. In this regard, a recent work by Castrén and Rancan (2014) has introduced the concept of macro-network of financial exposures (recently revisited by Perillo and Battiston (2017); Perillo and Battiston (2018); Stolbova et al. (2018)), where nodes are the institutional sectors operating in the economy and links are the financial contracts outstanding among them. This macro-network is the result of an aggregation by institutional sector, meaning that macro-nodes (i.e., the institutional sectors) represent an aggregation of the micro-networks of financial exposures outstanding among the institutions or individuals operating within the specific institutional sectors. For this reason, each node in the macro-network should be regarded as a network of microbased granular financial exposures. Moreover, according to the same argument made for the micro-network (i.e., financial contracts among institutions or individuals, and thus, among institutional sectors, occur through different kinds of financial instruments), the macro-network of financial exposures may be regarded as a multilayer network of financial exposures, where layers correspond to different financial instruments. In this regard, Perillo and Battiston (2018) argue that the analysis of the euro area economy as a multilayer financial network allows one to obtain relevant insights on the challenging problem of estimating the financial interdependencies existing between the banking sector and both the real and the financial sectors. In fact, this approach enables one to account for the relevant direct and indirect exposures via the different financial instruments considered together and provides a map of the potential channels through which distress may propagate as a consequence of shocks of different nature. Further, Perillo and Battiston (2018) provide empirical evidence supporting the fact that these insights could not be obtained with a single-layer analysis, and that, by looking at a single layer at a time, one may fail to detect instability, underestimating the systemic importance and the vulnerability of the nodes in the network.

Building on Castrén and Rancan (2014) and constrained by the lack of data on granular financial exposures, we regard the euro area economy as a macro-network of financial exposures, where nodes are the institutional sectors described in Section 2.1. In line with the related literature, this macro-network of financial exposures is the result of an aggregation on two dimensions: by country and by institutional sector. In other words, the euro area macro-network of financial exposures is obtained by aggregating i) the nineteen macro-networks of financial exposures among the institutional sectors operating in the nineteen countries belonging to the Eurozone and their mutual interactions, and ii) the micro-based granular financial exposures among the different institutions operating within every institutional sector. Moreover, building on Perillo and Battiston (2018), we regard the euro area macro-network of financial exposures as a multilayer weighted network in which the multiple layers correspond to different financial instruments (i.e., loans and deposits, bonds, equity, and insurance and pension schemes). Links are the financial dependencies through which the different institutional sectors are tied to each other. In particular, links start from the institutional sector that holds the financial instrument and point to the sector that issued it. Weights correspond to our estimation of the financial exposures existing 
among the different institutional sectors through the different financial instruments, based on the balance sheet outstanding amount at the end of the period (stock). Formally, direct exposures among financial actors are estimated in the following way:

$$
D E_{i}=\left(\sum_{j=1}^{n} \beta_{i j}^{\text {Loans\&deposits }}+\beta_{i j}^{\text {Securities }}+\beta_{i j}^{\text {Equity }}+\beta_{i j}^{\text {Insurance\&pensionschemes }}\right)+R_{i},
$$

where $\beta_{i j}$ denotes the monetary value of the exposure of institutional sector $i$ to institutional sector $j$ via the different considered financial instruments. Further, $n$ is the number of institutional sectors (or nodes) considered in our analysis, while $R_{i}$ is a residual, accounting for the exposures to sectors or via instruments that we are not considering in our analysis.

In order to investigate the implications of QE both in terms of stimulation of the real economy and intra-financial interconnectedness, first we perform a comprehensive analysis of the euro area economy as a multilayer macro-network. In particular, we focus both on the third quarter of 2014, which we identify as the reference "snapshot" prior to the implementation of QE, as the first purchase program included in the APP started on 20th October 2014, and on the second quarter of 2017. This analysis allows us to estimate the direct and indirect financial interdependencies existing between the banking sector and both the real and the financial sectors via the different financial instruments considered together, prior to and after the implementation of QE. Further, this analysis provides us with a map of the potential channels through which distress may propagate as a consequence of shocks of different nature that we identify both prior to and after the implementation of the policy under analysis. Second, we compute different network statistics, both with reference to the multilayer macro-network of financial exposures concerning September 2014 and with reference to the multilayer macro-network of financial exposures concerning June 2017. In particular, building on Opsahl et al. (2010), we compute a generalization of the weighted and non-weighted version of the degree, closeness, and betweenness centrality measures. These centrality measures are able to take into account both the number of ties, as typical for non-weighted network measures, and the tie weights, as common in weighted network metrics, allowing for attributing different relative importance to the number of ties compared to the tie weighs in contributing to the centrality of a node. More specifically, with reference to the degree centrality, Opsahl et al. (2010) propose the following measures as a compromise between the weighted and non-weighted degree metrics:

$$
C_{D-\text { out }}^{w \alpha}(i)=\left(k_{i}^{\text {out }}\right)^{(1-\alpha)} \times\left(s_{i}^{\text {out }}\right)^{\alpha}
$$

and

$$
C_{D-i n}(i)^{w \alpha}=\left(k_{i}^{i n}\right)^{(1-\alpha)} \times\left(s_{i}^{i n}\right)^{\alpha},
$$

where $k_{i}^{\text {out }}$ and $k_{i}^{\text {in }}$ correspond to the out-degree and in-degree centrality measures first introduced by Freeman (1978). These measures are generally computed on nonweighted networks, as they are defined as the number of links that originate from node $i$ and the number of links directed to node $i$, respectively. Further, $s_{i}^{\text {out }}$ and $s_{i}^{\text {in }}$ 
correspond to the out-strength and in-strength centrality measures, first introduced by Barrat et al. (2004), which are computed on weighted networks, as they are defined as the sum of the weights attached to the outgoing links and to the incoming links of a generic node $i$, respectively. Lastly, $\alpha$ is a tuning parameter that allows for attributing different relative importance to the number of ties compared to the tie weighs in contributing to the centrality of a node. For example, when $\alpha=0, C_{D-\text { out }}(i)^{w \alpha}$ and $C_{D-i n}(i)^{w \alpha}$ values equal the node out- and in-degree (i.e., $k_{i}^{\text {out }}$ and $k_{i}^{i n}$ ), while when $\alpha=1$, the $C_{D-o u t}(i)^{w \alpha}$ and $C_{D-i n}(i)^{w \alpha}$ values equal the node out- and in-strength (i.e., $s_{i}^{\text {out }}$ and $s_{i}^{\text {in }}$ ). Therefore, setting $\alpha=0.5$ implies that the same importance is attributed to number of ties and tie weights in contributing to the centrality of a node $i$. Similarly to the degree centrality, Opsahl et al. (2010) propose the following formulations for the closeness and the betweenness centrality measures, respectively:

$$
C_{C}^{w \alpha}(i)=\left(\sum_{j=1}^{n} d^{w \alpha}(i, j)\right)^{-1},
$$

where $d^{w \alpha}(i, j)$ is shortest path between two nodes $i$ and $j$ defined as:

$$
d^{w \alpha}(i, j)=\min \left(\frac{1}{\left(w_{i h}\right)^{\alpha}}+\cdots+\frac{1}{\left(w_{h j}\right)^{\alpha}}\right),
$$

and

$$
C_{B}^{w \alpha}(i)=\frac{g_{j k}^{w \alpha}(i)}{g_{j k}^{w \alpha}},
$$

where $g_{j k}^{w \alpha}$ is the number of shortest paths between two nodes $\left(d^{w \alpha}(j, k)\right), g_{j k}^{w \alpha}(i)$ is the number of those paths that go through node $i$, and $\alpha$ is the aforementioned tuning parameter.

Further, building on Kaushik and Battiston (2013) and Junker and Schreiber (2011), we compute the weighted version of the Katz centrality to measure the influence of nodes, taking into account the total number of walks between a pair of nodes, given by:

$$
C_{K}^{w}(i)=\sum_{k=1}^{\infty} \sum_{j=1}^{n} \gamma^{k}\left(A^{k}\right)_{i j}
$$

where $A$ is the weighted adjacency matrix of the network under consideration, the powers of $A$ indicate the presence (or absence) of links between two nodes through intermediaries, and $\gamma$ is an attenuation factor, ${ }^{14}$ employed to penalize connections made with distant neighbors.

Lastly, building on Bardoscia et al. (2015), we estimate a measure of nodes' vulnerability coming from the generalized version of the DebtRank algorithm. The DebtRank algorithm is a measure of systemic impact that takes recursively into account the effect of the distress of an initial node across the whole network (Battiston et al. 2012b), proposed in its original formulation by Battiston et al. (2012b).

\footnotetext{
${ }^{14}$ The attenuation factor has to be chosen such that it is smaller than the reciprocal of the absolute value of the largest eigenvalue of the adjacency matrix $A$.
} 
The generalized DebtRank financial contagion model as proposed by Bardoscia et al. (2015) is an extension of the original algorithm to allow distress to be propagated along the paths in the network, including all cycles ${ }^{15}$ (Visentin et al. 2016). The financial distress propagation process proposed by Bardoscia et al. (2015) is defined as follows:

$$
h_{i}(t+1)=\min \left\{1, h_{i}(t)+\sum_{j=1}^{n}(1-R R) l_{i j}^{b}\left[h_{j}(t)-h_{j}(t-1)\right]\right\},
$$

where $h_{i}(t+1)$ and $h_{i}(t)$ correspond to the individual vulnerability of node $i$ at time $t+1$ and at time $t$, respectively. Further, $R R$ is the recovery rate (i.e., the amount recovered through foreclosure or bankruptcy procedures in the event of a default, expressed as a percentage of face value). Lastly, $l_{i j}^{b}$ is the leverage ratio of node $i$ with respect to $j$, given by the ratio between the assets of node $i$ invested in node $j$ and the equity (i.e., difference between assets and liabilities) of node $i$, while $h_{j}(t)$ and $h_{j}(t-1)$ correspond to the vulnerability of node $j$ at time $t$ and $t-1$, respectively.

\subsection{Measures of financialization}

Building on the existing literature on financialization, first we identify and compute some standard indicators able to capture the phenomenon of financialization in the euro area. Second, we propose some novel measures of financialization that we derive from our multilayer analysis of the euro area macro-network of financial exposures. As mentioned in Section 1, the term financialization is commonly used to capture the pervasive role played by finance in modern economies (Turner 2017). However, the financialization-related literature provides various definitions of this phenomenon. For example, according to Epstein (2001), "financialization refers to the increasing importance of financial markets, financial motives, financial institutions, and financial elites in the operation of the economy and its governing institutions, both at the national and international level" (as referenced by Palley (2013)). (Krippner 2005) defines financialization as "a pattern of accumulation in which profits accrue primarily through financial channels rather than through trade and commodity production", while (Stockhammer 2004) defines it as "the increased activity of non-financial businesses on financial markets" (as referenced by Assa (2012)). Associated with the multiple existing definitions of the phenomenon of financialization is a wide range of indicators employed in the related literature to measure its extent. In fact, many studies propose different measures of the size of the formal financial system relative to economic activity, i.e., financial deepening or financial depth, to quantify the level of financial development and investigate the relationship between financialization and growth (King and Levine 1992). In particular, among

\footnotetext{
${ }^{15}$ The extension also allows the mathematical intractability connected with the fact that the presence of a cycle in the network leads to an infinite number of reverberations of the impact of a node to the others and back to itself to be overcome, thus enabling a full exploitation of the linearity underlying the model, with important consequences for the analysis of the stability of the system (Visentin et al. 2016; Battiston et al. 2016a; Bardoscia et al. 2015; 2017).
} 
others, McKinnon (2010) employs the ratio of M2 ${ }^{16}$ to GDP, while Gelb (1989) the ratio of M $3^{17}$ to GDP (King and Levine 1992). Neal (1990) uses i) M1 to GDP, ii) M3 to GDP, and iii) M3 minus M1 to GDP, while Goldsmith (1975) uses the ratio of financial institutions' assets to Gross National Product (GNP) (King and Levine 1992). Moreover, King and Levine (1992) measure the size of the financial system with four indicators. The first two measures are i) the ratio of M1 to GDP, commonly used as a measure of monetary depth and ii) the ratio of liquid liabilities of the financial system ${ }^{18}$ to GDP, representing the overall financial depth. ${ }^{19}$ Further, they employ iii) the ratio of quasi-liabilities of the financial system ${ }^{20}$ to GDP, defined as the non-monetary financial depth, and iv) the ratio of domestic credit to the private sector $^{21}$ to GDP. King and Levine (1993b) and King and Levine (1993a) use four indicators of financial development. The first two measures are i) the ratio of liquid liabilities to GDP and ii) the ratio of deposit money banks' domestic assets to deposit money banks' domestic assets plus central banks' domestic assets. Moreover, they use iii) the ratio of claims on the non-financial private sector to total domestic credit, excluding credit to banks, ${ }^{22}$ and iv) the ratio of claims on the non-financial private sector to GDP. ${ }^{23}$ Lastly, more recent examples of financialization measures are i) the portfolio income of non-financial firms and profits of financial versus non-financial firms (Krippner 2005), ii) the interest and dividend income of non-financial businesses (Stockhammer 2004), and iii) the financial sector's share of profits (Freeman 2010). Further instances are iv) the ratio of financial sector's profits to the wages and salaries of all private sector workers (Freeman 2010), v) the ratio of financial assets to GDP (Freeman 2010), vi) the size of the financial sector as a percentage of GDP (Kedrosky and Stangler 2011), and vii) the ratio of bank assets to GDP (Turner 2017). Among this variety of indicators proposed by the financialization-related literature, we focus on two standard measures able to capture the level of financialization and

\footnotetext{
${ }^{16} \mathrm{M} 2$ is the so-called "intermediate" monetary aggregate that comprises currency in circulation and overnight deposits (i.e., M1) plus deposits with an agreed maturity of up to two years and deposits redeemable at notice of up to three months (European Central Bank 2017a).

${ }^{17} \mathrm{M} 3$ is the so-called "broad" monetary aggregate that comprises M2 plus repurchase agreements, money market fund shares and units, as well as debt securities with a maturity of up to two years (European Central Bank 2017a).

${ }^{18}$ Liquid liabilities equal M1 plus interest bearing liabilities of the banking system, plus demand and interest bearing liabilities of non-bank financial intermediaries, e.g., saving banks, postal saving institutions, finance companies, etc. (King and Levine 1992).

${ }^{19}$ The assumption behind this measure is that the size of the financial sector is positively correlated with the provision of financial services (King and Levine 1993b).

${ }^{20}$ Quasi-liabilities equal liquid liabilities minus M1 (King and Levine 1993b).

${ }^{21}$ The domestic credit to the private sector consists of claims on the private sector by central and deposit money banks (King and Levine 1993b).

${ }^{22}$ This measure equals the amount of credit issued to private enterprises divided by credit issued to central and local governments plus credit issued to public and private enterprises (King and Levine 1993b). Higher values of this indicator reflect a redistribution of credit from public enterprises and government to private firms (King and Levine 1993b).

${ }^{23}$ This measure equals the amount of credit issued to private enterprises divided by GDP (King and Levine 1993b). Higher values of this measure indicate more credit to the private sector as a share of GDP (King and Levine 1993b).
} 
the subsequent pervasive role played by finance in the economy: i) the ratio of financial assets to GDP and ii) the ratio of bank assets to GDP. Moreover, according to Greenwood and Scharfstein (2013), one of the most relevant drivers in the dramatic acceleration of finance has been the striking growth in asset management activities and profits. Since this factor comes along with the increased complexity of the financial system's activities (Turner 2017), we propose some measures that could capture this complexity. In particular, since a large part of these complex activities is intrafinancial (D'Errico et al. 2018), we focus on estimating the size of the intra-financial market. To do so, building on the multilayer macro-network of financial exposures, we derive the breakdown of financial institutions' total financial assets by counterparty macro sector (i.e., financial, real, public, and non-euro area sector). Then, we estimate i) the breakdown of financial institutions' loans and deposits by counterparty sector, as well as ii) the breakdown of financial institutions' bonds by counterparty sector, and iii) the breakdown of financial institutions' equity by counterparty sector. ${ }^{24}$ We compute these breakdowns both from a static and a dynamic perspective. However, our dynamic empirical analysis focuses in particular on the fraction of intra-financial loans and deposits, securities, and equity compared to the fraction of loan and deposit, security, and equity contracts outstanding between the financial and the real sector for two main reasons. First, these measures enable us to investigate the transmission of resources to the real economy through the increase in the interactions between the financial sector and the real sector, via loans and deposits, securities, and equity, since the implementation of QE. Second, these indicators allow us to explore the process of financialization of the euro area economy through the increase of the intra-financial interactions via loans and deposits, securities, and equity, since the implementation of QE.

\section{Data}

The empirical analysis has been conducted both from a static and a dynamic perspective, considering the eight institutional sectors described in Section 2.1 operating in the nineteen European Union's Member States belonging to the EMU. In particular, on the one hand, the static analysis focuses on the third quarter of 2014 and on the second quarter of 2017 that we identify as the "snapshots" prior to and after the implementation of QE, respectively. On the other hand, the dynamic analysis has been conducted with regard to the period spanning from the fourth quarter of 2012 to the second quarter of 2017 (both quarters included). Our analysis is based on several network variables and a macroeconomic variable. We define as network variables the financial exposures through which the institutional sectors are tied to each other. In particular, our study relies upon the financial dependencies among the different institutional sectors under analysis, via loans and deposits, securities,

\footnotetext{
${ }^{24}$ Unfortunately, our dataset does not contain data on Over-The-Counter (OTC) derivatives and it includes data on non-OTC derivatives only at an aggregate level. Therefore, available data do not allow us to investigate the breakdown of financial institutions' derivative contracts by counterparty sector.
} 
shares and other equity, and insurance and pension schemes, with a particular focus on the links between the financial and real sector and on intra-financial links. Network variables have been obtained from ECB Statistical Data Warehouse (European Central Bank 2017c), by combining different sources of data ${ }^{25}$ (e.g., balance sheet data of the different institutional sectors, sector accounts, panel data on the mutual financial exposures among sectors across some financial contracts, called "who-towhom data"). The financial dependencies are estimated as the end-of-quarter data based on the institutional sectors' balance sheet outstanding amounts of loans and deposits, securities, equity, and insurance and pension schemes. However, it is worth mentioning that data on financial exposures via bonds, equity, and insurance and pension schemes are less detailed compared to data on loans and deposits. In fact, in order to be able to disaggregate the time evolution of some exposures via securities and equity by issuer sector, we have relied on the who-to-whom data. However, this dataset covers only a short time period, spanning from the fourth quarter of 2013 to the second quarter of 2017 (both quarters included) and does not include data on insurance and pension schemes. For these reasons, the dynamic analysis of financial dependencies via bonds and equity refers to the period 2013Q4-2017Q2 and financial dependencies via insurance and pension schemes are analyzed only from a static perspective. Moreover, since data on insurance and pension schemes are available only at an aggregate level (i.e., as total insurance and pension schemes held and issued by every institutional sectors), static financial exposures via this instrument have been reconstructed by assuming their proportionality to institutional sectors' total holdings and issuances of the same instrument. As regards the macroeconomic variable, our study relies upon the time evolution of the euro area Gross Domestic Product (GDP). The GDP series has been obtained from European Central Bank (2017c) and it is chain-linked volume and working day and seasonally adjusted.

\section{Exploratory results}

\subsection{Overview of the euro area economy}

Our analysis focuses on the interactions among the different euro area institutional sectors and Rest of the World via five categories of financial instruments: i) loans and deposits, ii) debt securities, iii) shares and other equity, iv) insurance and pension schemes, and v) all remaining assets. The latter category includes i) monetary gold and Special Drawing Rights (SDRs), and ii) other accounts receivable and financial derivatives. ${ }^{26}$ Figure 1 illustrates the breakdown of euro area financial assets by instrument type, with reference to the second quarter of 2017. As can be seen from Fig. 1, the financial instruments contributing the most to total euro area financial

\footnotetext{
${ }^{25}$ Please note that all data sources in this paper have been last accessed on December 2017.

${ }^{26}$ Unfortunately, data on other accounts receivable and financial derivatives are available only at an aggregate level. Therefore, available data don't allow us to investigate the interactions among the different institutional sectors operating in the euro area and Rest of the World via the aforementioned categories of financial instruments.
} 


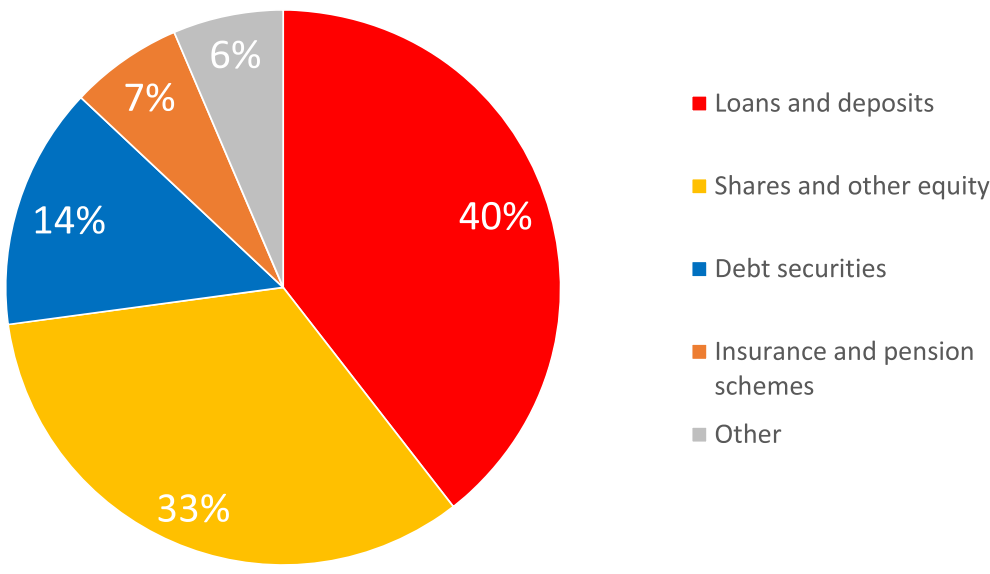

Fig. 1 Breakdown of euro area financial assets by instrument type; June 2017. Breakdown of euro area financial assets by instrument type, i.e., short-term and long-term loans and deposits (in red), short-term and long-term private and public debt securities (in blue), listed, unlisted, and investment funds' shares and other equity (in yellow), insurance and pension schemes (in orange), and other financial assets (in grey). The residual category "other" includes i) monetary gold and Special Drawing Rights (SDRs) $(0.35 \%$ of euro area financial assets) and ii) Other accounts receivable and financial derivatives (6.07\% of euro area financial assets). Source: authors' computations based on (European Central Bank 2017c)

assets are loans and deposits (40\% of euro area financial assets), followed by shares and other equity (33\% of euro area financial assets). Further, debt securities constitute $14 \%$ of euro area financial assets, while insurance and pension schemes and other financial assets represent $7 \%$ and $6 \%$ of euro area financial assets, respectively. More specifically, a further breakdown of the above categories of financial instruments suggests that loans and deposits amount to about $20 \%$ and $20 \%$ of euro area financial assets, respectively. Within the share and other equity market, unlisted shares amount to about $20 \%$ of euro area financial assets, followed by investment funds' shares (about $7 \%$ of euro area financial assets) and listed shares (about $6 \%$ of euro area financial assets). Debt securities are mostly composed of long-term securities (amounting to about 13\% of euro area financial assets) rather than short-term securities (about $1 \%$ of euro area financial assets). Lastly, the residual category "other" is mostly composed of other accounts receivable and financial derivatives (amounting to about $6 \%$ of euro area financial assets), followed by monetary gold and Special Drawing Rights (SDRs) (0.35\% of euro area financial assets).

Figures 2 and 3 illustrate the breakdown of euro area institutional sectors' and Rest of the World's financial assets and liabilities by instrument type and their net financial worth (i.e., the difference between financial assets and financial liabilities), with reference to 2014Q3 and 2017Q2. As can be seen from Figs. 2 and 3, on the one hand, in September 2014, loans and deposits were mostly granted/held by Monetary Financial Institutions and Households, while in June 2017, by Monetary Financial Institutions and Rest of the World. On the other hand, both in 2014Q3 and 2017Q2 loans and deposits were mostly owed by Monetary Financial Institutions and Non-Financial Corporations. As regards debt securities, while Monetary 


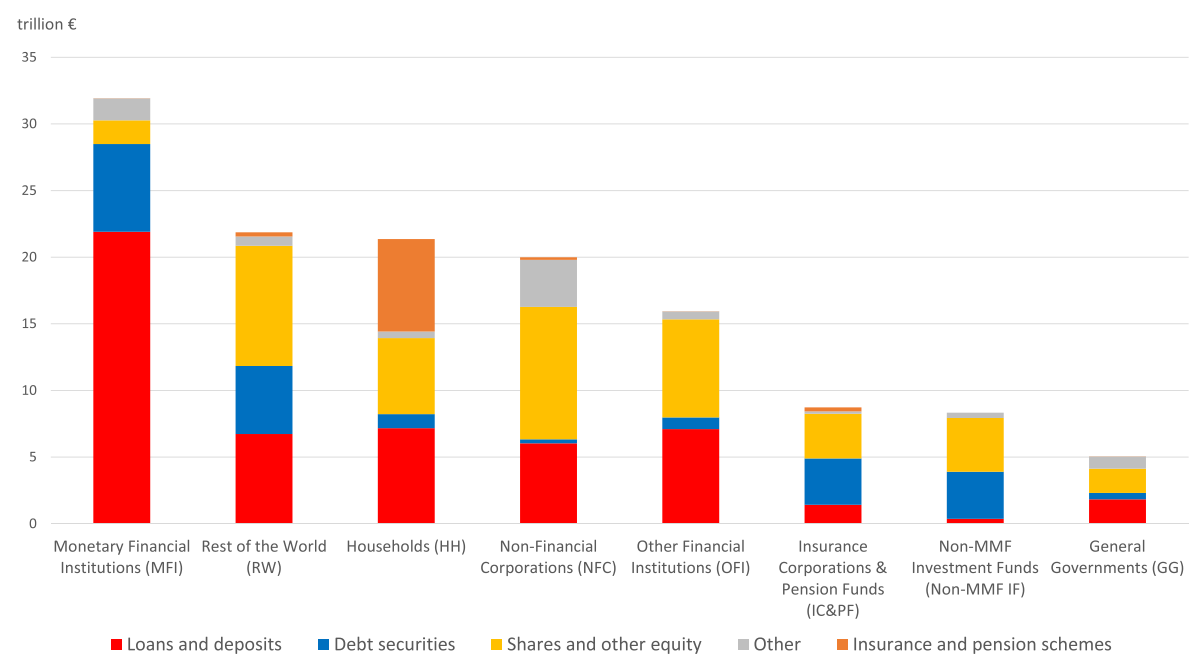

(a)

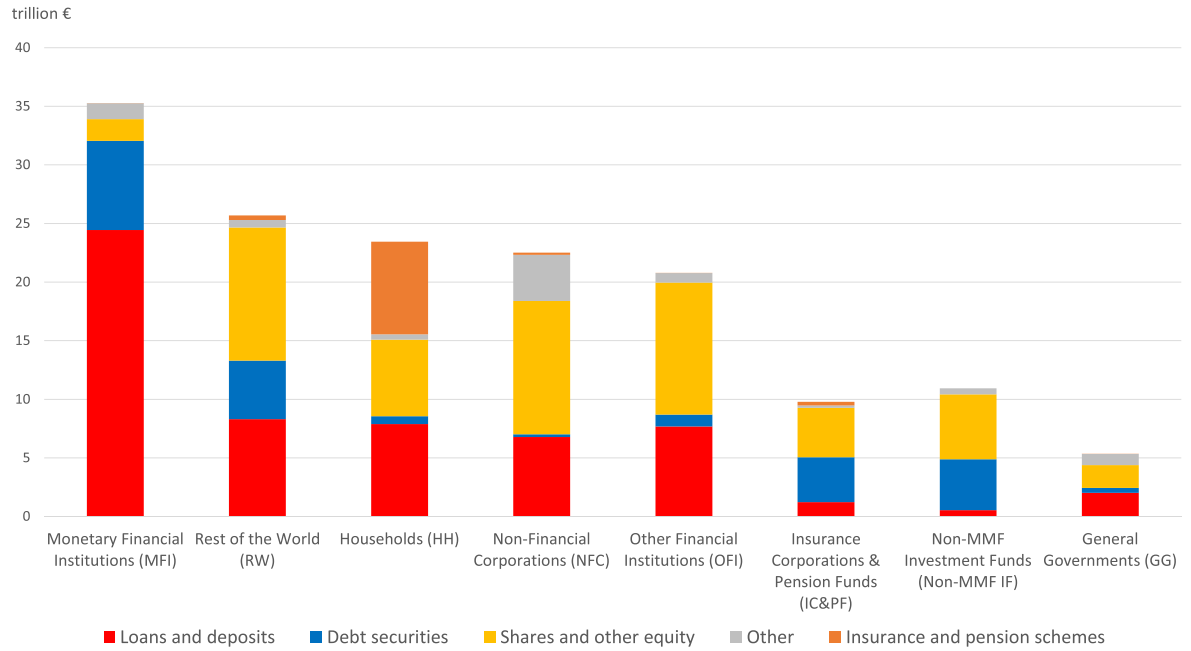

(b)

Fig. 2 Breakdown of euro area institutional sectors' and Rest of the World's financial assets by instrument type; (a) September 2014 (b) June 2017. Breakdown of euro area institutional sectors' and Rest of the World's financial assets by instrument type, i.e., short-term and long-term loans and deposits (in red), short-term and long-term private and public debt securities (in blue), listed, unlisted and investment funds' shares and other equity (in yellow), insurance and pension schemes (in orange), and other financial assets (in grey). The residual category "other" includes i) monetary gold and Special Drawing Rights (SDRs) (totally held by Monetary Financial Institutions) and ii) other accounts receivable and financial derivatives (mainly held by Non-Financial Corporations). Source: authors' computations based on (European Central Bank 2017c) 


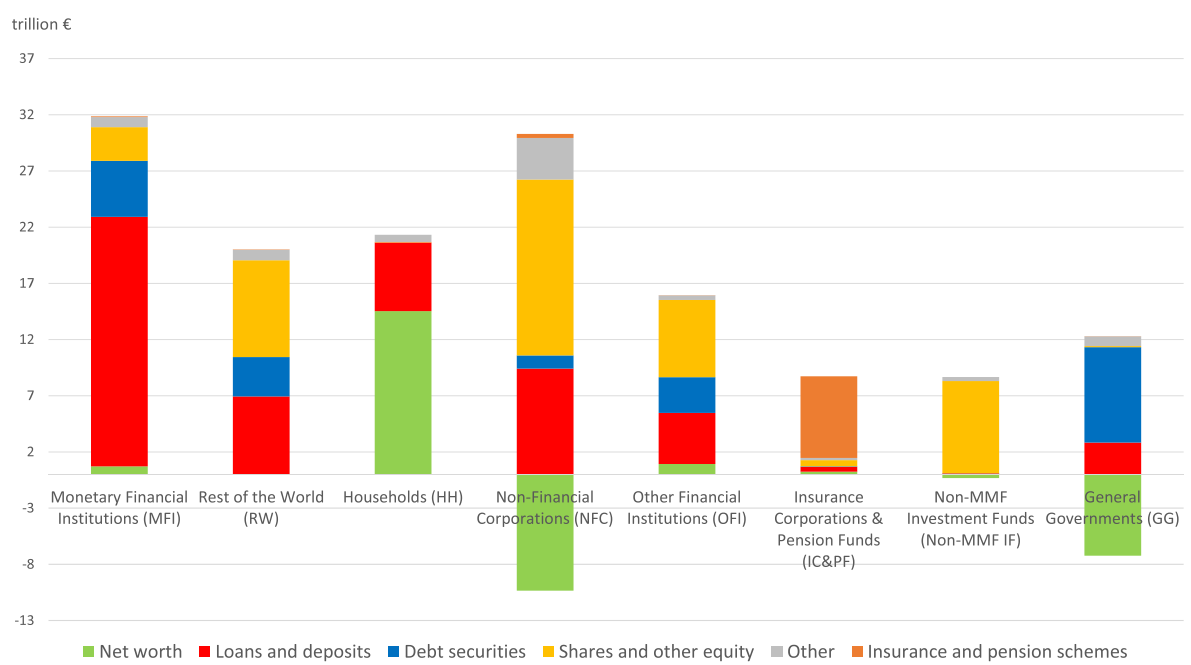

(a)

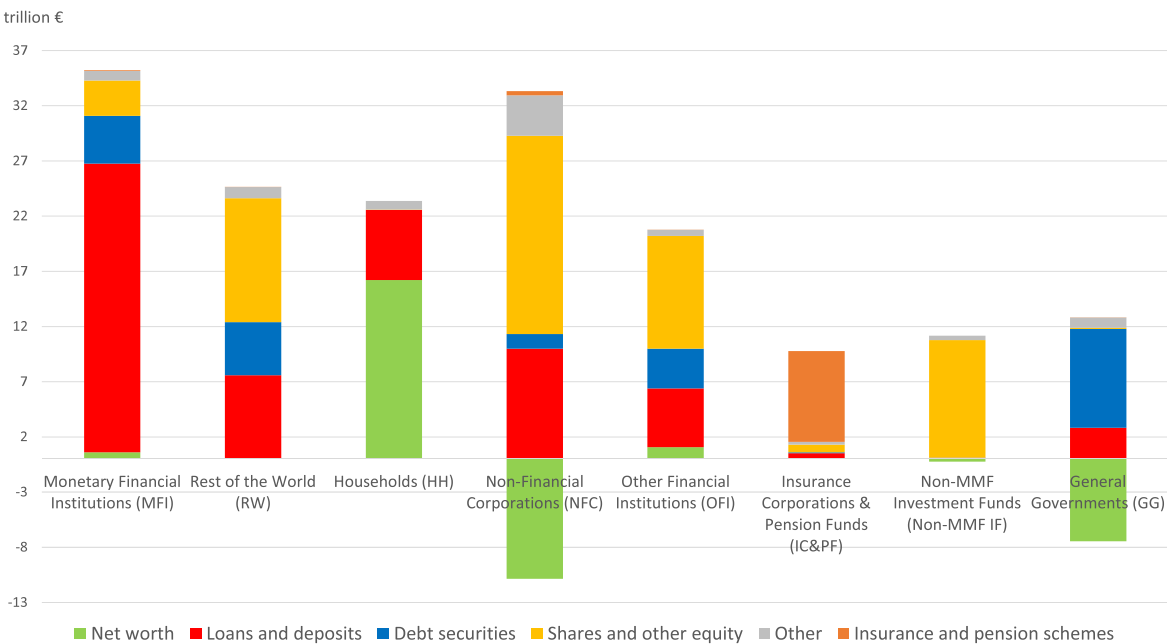

(b)

Fig. 3 Breakdown of euro area institutional sectors' and Rest of the World's financial liabilities by instrument type and their net financial worth; (a) September 2014 (b) June 2017. Breakdown of euro area institutional sectors' and Rest of the World's financial liabilities by instrument type, i.e., short-term and long-term loans and deposits (in red), short-term and long-term private and public debt securities (in blue), listed, unlisted and investment funds' shares and other equity (in yellow), insurance and pension schemes (in orange), and other financial assets (in grey), and euro area institutional sectors' net financial worth (in light green). The residual category "other" includes other accounts receivable and financial derivatives (mainly issued by Non-Financial Corporations). Source: authors' computations based on (European Central Bank 2017c) 
Financial Institutions and Rest of the World were the main holders with reference to both 2014Q3 and 2017Q2, General Governments and Monetary Financial Institutions were the main issuers in 2014Q3, while General Governments and Rest of the World were the main issuers in 2017Q2. The main players of the equity market were Non-Financial Corporations, Rest of the World, and Other Financial Institutions on the asset side (holdings), both in September 2014 and June 2017. On the liability side (issuances), a key role was played by Non-Financial Corporations, Rest of the World, Non-MMF Investment Funds, and Other Financial Institutions, both in September 2014 and June 2017. Regarding insurance and pension schemes, they were mostly held by Households and issued by Insurance Corporations and Pension Funds, both in 2014Q3 and 2017Q2. Lastly, concerning the euro area institutional sectors' net financial worth, it was positive for all of them, excluding Non-Financial Corporations, General Governments (significantly negative), and Non-MMF Investment Funds (slightly negative). In particular, Households exhibited the highest net financial worth, while Non-Financial Corporations the lowest, with reference to both 2014Q3 and 2017Q2. The net financial worth of an institutional entity summarizes the entity's ability to honor fully its obligations, as assets complement expected future revenues that could be used to pay down outstanding debt (OECD 2017). As a consequence, General Governments' and Non-Financial Corporations' negative net

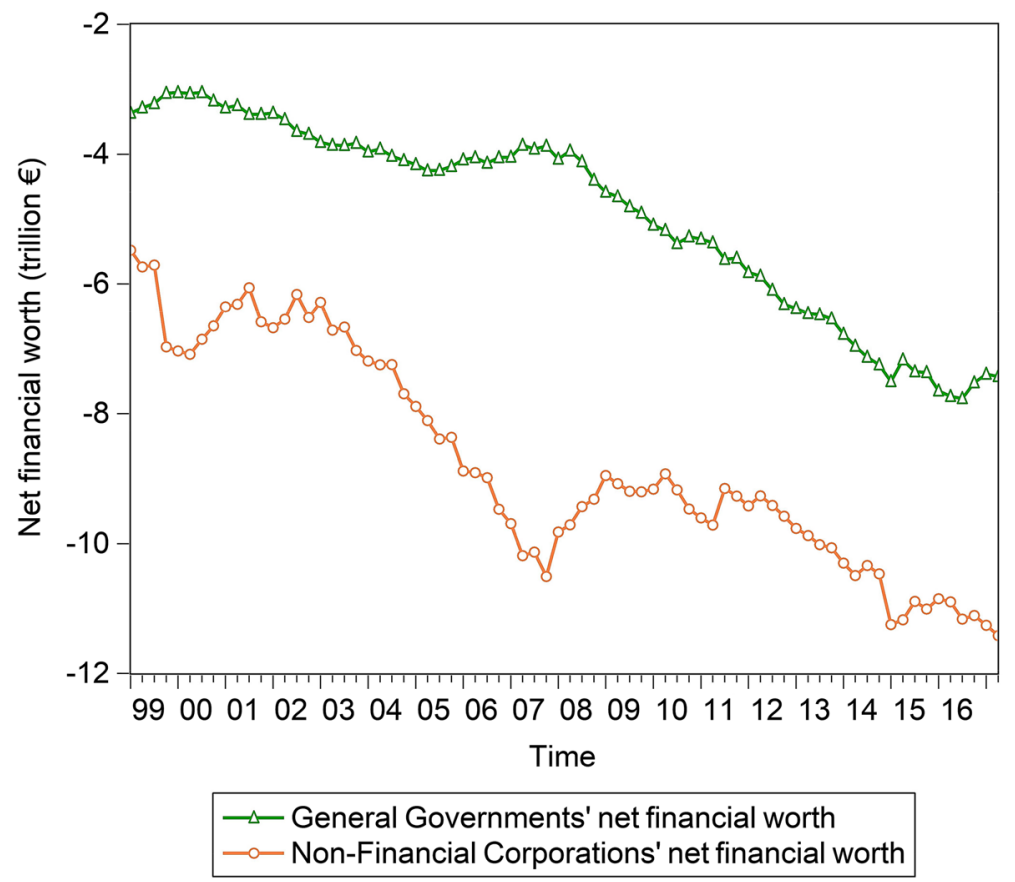

Fig. 4 General Governments' and Non-Financial Corporations' net financial worth; 1999Q1-2017Q2. Time series of General Governments' (in green) and Non-Financial Corporations' (in orange) net financial worth (i.e., difference between financial assets and financial liabilities) over the reference period 1999Q12017Q2. Source: authors' computations based on (European Central Bank 2017c) 
financial worth may be a sign of excessive indebtedness that may lead to the inability to honor fully their outstanding obligations. In particular, on the one hand, as regards General Governments, a negative net financial worth, but especially its worsening over time, is a sign of a fragile fiscal position that requires either tax increases or reductions in expenditure, as well as a combination of both (OECD 2017). In this regard, (OECD 2017) provides empirical evidence of a deterioration of General Governments' net financial worth across the OECD countries over the period 2007-2015 (by 31.7 percentage points), reflecting the combination of negative growth, larger deficits and higher public debt, which characterized the post-crisis period (OECD 2017). This empirical evidence is consistent with the time series of euro area General Governments' net financial worth over the reference period 1999Q1-2017Q2, represented with a green line in Fig. 4. On the other hand, regarding Non-Financial Corporations, their negative net financial worth is a clear sign of the development of the euro area economy as a debt-intensive economy, which relies on the continuous supply of credit, without which many companies would stop investing and in some cases default. Indeed, as shown by the time series of euro area Non-Financial Corporations' net financial worth over the reference period 1999Q1-2017Q2, represented with an orange line in Fig. 4, NFC's current level of negative net financial worth is the result of a progressive worsening of the difference between financial assets and liabilities that occurred in the years prior to the onset of the global financial and economic crisis. The latter improved in 2008 and remained nearly stable until 2012, when it restarted its downward movement, which has lasted until the end of our dataset (i.e., the second quarter of 2017). Although a negative net financial worth may negatively influence financing opportunities and stifle future business growth, it does not necessarily imply bankruptcy. Moreover, its assessment depends on firm-level balance sheet information and characteristics such as age of the firm and duration of the situation of negative net financial worth, with reference to Non-Financial Corporations, as well as country-level indicators and variables, regarding General Governments. Therefore, a deeper analysis of the implications of the negative net financial worth at an aggregate level would require a disaggregation of the institutional sector NonFinancial Corporations and General Governments, by institution and by country, respectively.

\subsection{The euro area macro-network of financial exposures}

In order to investigate i) to what extent QE may generate net flows of additional resources to the real economy and ii) to what extent QE may alter the pattern of intrafinancial exposures among financial actors, first of all, we examine the euro area multilayer macro-network of financial exposures. In particular, first, we separately investigate the different layers of the euro area multilayer macro-network of financial exposures, with a particular focus on direct exposures. Second, we focus on the comprehensive analysis of the euro area economy as a multilayer macro-network, by considering direct and indirect financial exposures among institutional sectors across the different financial instruments under analysis. In this regard, on the one hand, Figs. 5, 6, 7 and 8 illustrate the macro-networks of financial exposures among the different euro area institutional sectors and the rest of the world, with reference to 


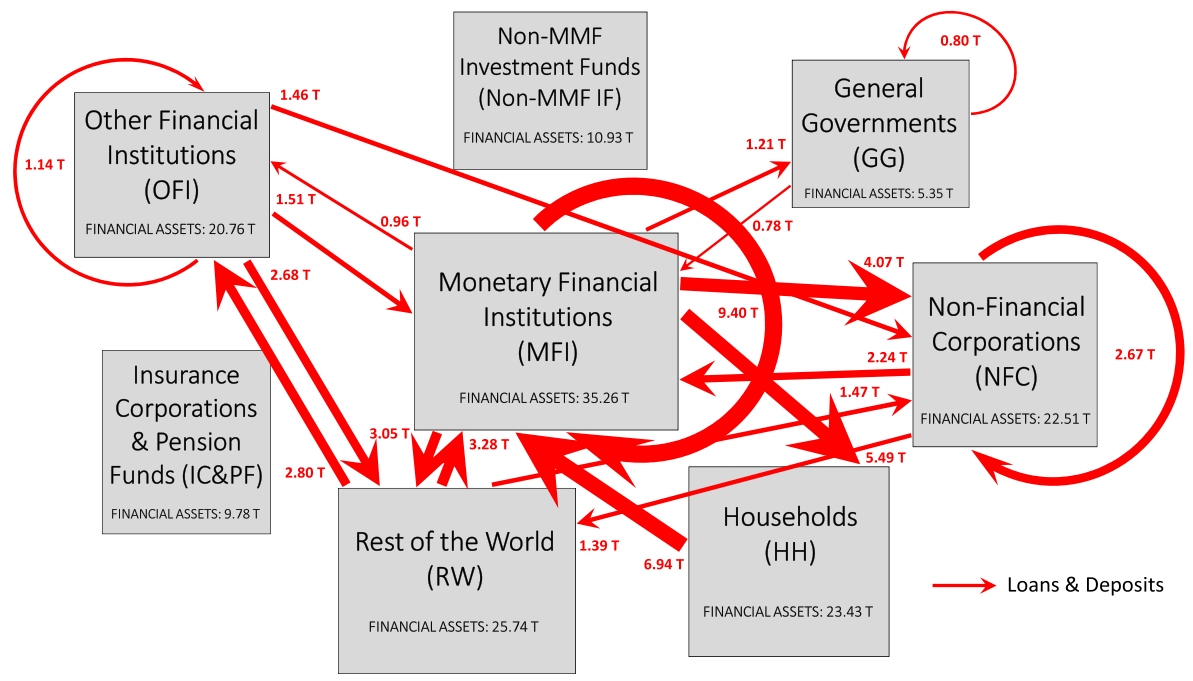

Fig. 5 The euro area macro-network of financial exposures via loans and deposits; June 2017. The macronetwork of financial exposures among the different institutional sectors operating in the euro area (i.e., Monetary Financial Institutions (MFI), Other Financial Institutions (OFI), Non-MMF Investment Funds (Non-MMF IF), Insurance Corporations and Pension Funds (IC\&PF), Households (HH), Non-Financial Corporations (NFC), and General Governments $(G G)$ ), and the Rest of the World $(R W)$, via short-term and long-term loans and deposits (represented with red links), with reference to the second quarter of 2017. Weights represent the outstanding financial exposures via loans and deposits of a source institutional sector to a target institutional sector and they are expressed in trillion euros. Links with a weight below $1 \%$ of total loans and deposits reported in the aforementioned institutional sectors' balance sheets have been removed. Source: authors' computations based on (European Central Bank 2017c)

the second quarter of 2017, via loans and deposits, debt securities, shares and other equity, and insurance and pension schemes, respectively. On the other hand, Fig. 9 illustrates the euro area as a multilayer macro-network of financial exposures via all the aforementioned financial instruments, with reference to the third quarter of 2014 and the second quarter of 2017. Links are the financial dependencies through which the different institutional sectors are tied to each other. In particular, links start from the institutional sector that holds the financial instrument and point to the sector that issued it. Weights correspond to the balance sheet outstanding amount at the end of the period (stocks) of loan and deposit, debt security, share and other equity, and insurance and pension scheme holdings/issuances. Since our main aim is to investigate whether some resources are actually transmitted from the banking system to the real economy via loan and deposit, bond, and equity contract or are staying into the financial system, our main focus is on the links starting from the node Monetary Financial Institutions.

With reference to the loan and deposit layer, as shown in Fig. 5, at the end of June 2017, the largest fraction of loans and deposits granted/held by Monetary Financial Institutions were bank-to-bank loans and deposits, followed by loans to Households and loans to Non-Financial Corporations, amounting to about 9.40, 5.49, and 4.07 trillion euros, respectively. Therefore, from the macro-network analysis of financial 
exposures via loans and deposits, we can notice that, although a large fraction of loans and deposits granted/held by Monetary Financial Institutions is intra-financial (10.36 trillion euros), a relevant portion of loans is granted by the banking sector to the real economy (9.56 trillion euros). Moreover, it is worth mentioning that the institutional sector Monetary Financial Institutions includes the Eurosystem. Consequently, although our dataset does not allow us to disaggregate loans from deposits, we can speculate that the 9.40 trillion euros of interbank loans and deposits includes also i) the money kept in form of reserves by banks at the Eurosystem and ii) the so-called TARGET balances. The latter category consists of intra-Eurosystem assets and liabilities of central banks' balance sheet resulting from net cross-border payments in the form of central bank reserves, via the Eurosystem's real-time gross settlement system, called TARGET2 (Eisenschmidt et al. 2017). More specifically, TARGET2 is a payment system that continuously settles euro-denominated payments on an individual transaction-by-transaction basis without netting (Eisenschmidt et al. 2017).

Regarding the debt security market, as we can see from Fig. 6, at the end of 2017Q2, the largest fraction of securities held by Monetary Financial Institutions, amounting to 3.33 trillion euros, were issued by General Governments. Further, Monetary Financial Institutions's debt securities issued by Monetary Financial

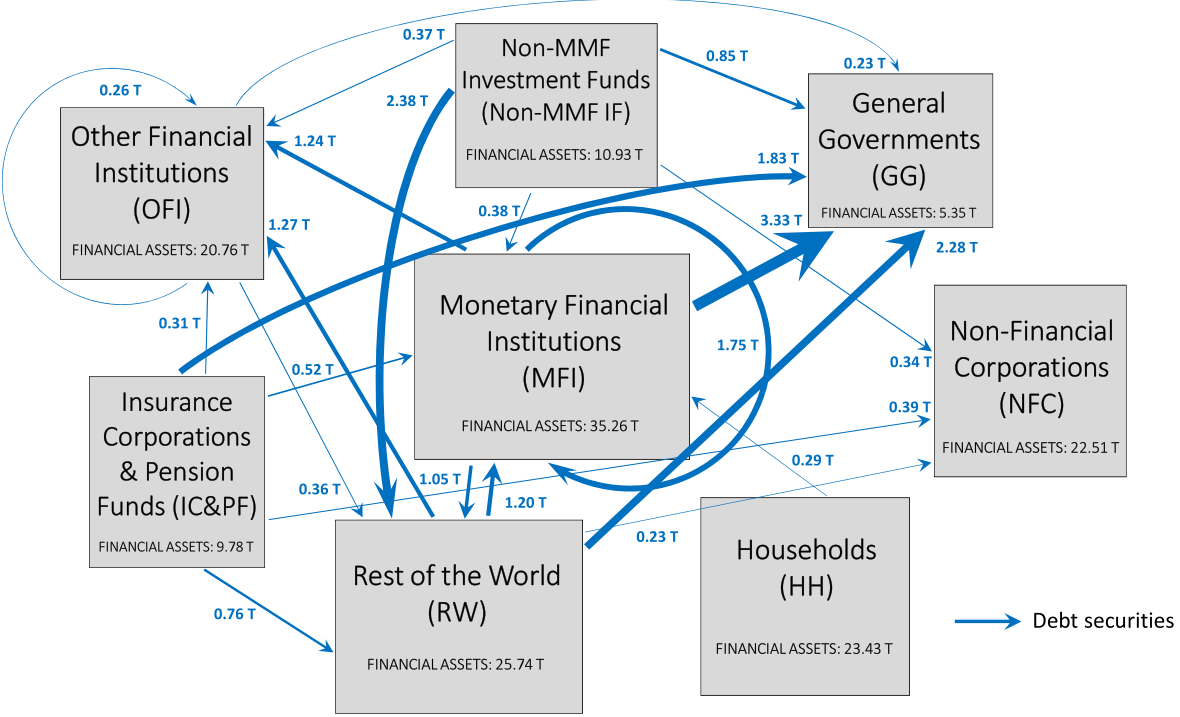

Fig. 6 The euro area macro-network of financial exposures via debt securities; June 2017. The macronetwork of financial exposures among the different institutional sectors operating in the euro area (i.e., Monetary Financial Institutions (MFI), Other Financial Institutions (OFI), Non-MMF Investment Funds (Non-MMF IF), Insurance Corporations and Pension Funds (IC\&PF), Households (HH), Non-Financial Corporations (NFC), and General Governments $(G G)$ ), and the Rest of the World $(R W)$, via short-term and long-term private and public debt securities (represented with blue links), with reference to the second quarter of 2017. Weights represent the outstanding financial exposures via debt securities of a source institutional sector to a target institutional sector and they are expressed in trillion euros. Links with a weight below $1 \%$ of total debt securities held and issued by the aforementioned institutional sectors have been removed. Source: authors' computations based on (European Central Bank 2017c) 


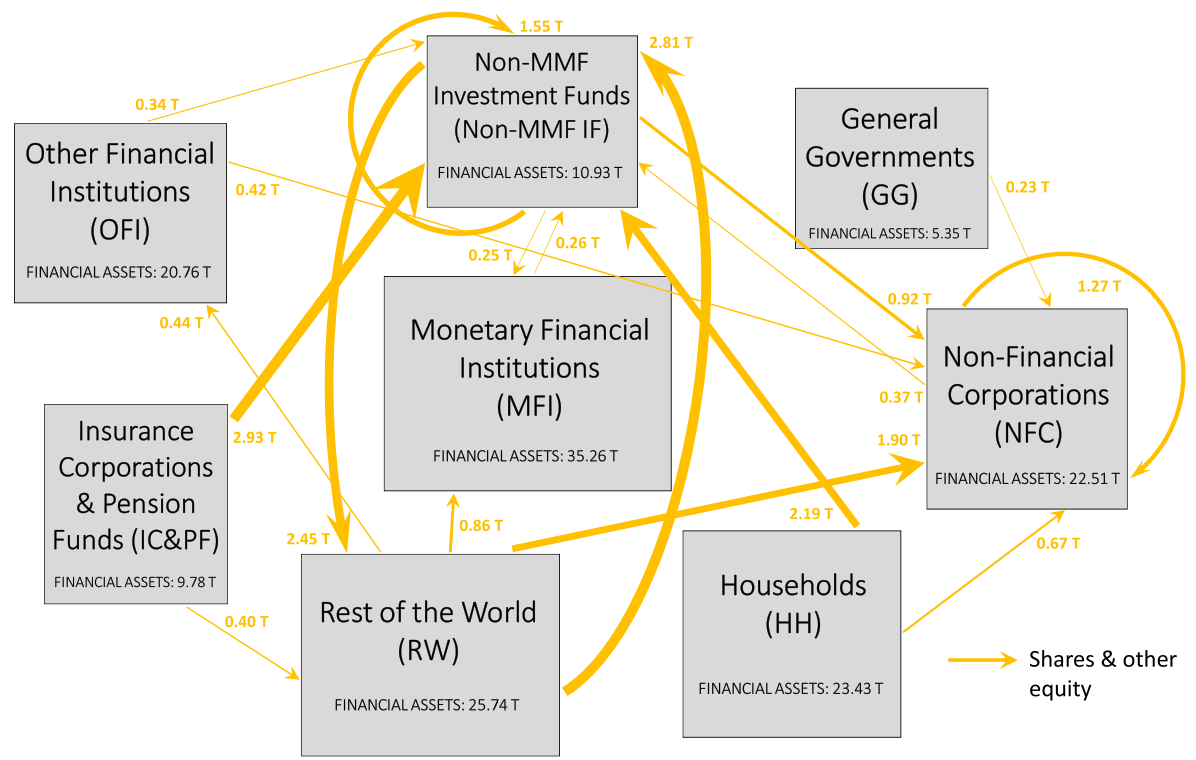

Fig. 7 The euro area macro-network of financial exposures via shares and other equity; June 2017. The macro-network of financial exposures among the different institutional sectors operating in the euro area (i.e., Monetary Financial Institutions (MFI), Other Financial Institutions (OFI), Non-MMF Investment Funds (Non-MMF IF), Insurance Corporations and Pension Funds (IC\&PF), Households (HH), NonFinancial Corporations (NFC), and General Governments $(G G)$ ), and Rest of the World (RW), via listed, and investment funds' shares and other equity (represented with yellow links), with reference to the second quarter of 2017. Weights represent the outstanding financial exposures via shares and other equity of a source institutional sector to a target institutional sector and they are expressed in trillion euros. Links with a weight below $1 \%$ of total shares and other equity held and issued by the aforementioned institutional sectors have been removed. Source: authors' computations based on (European Central Bank 2017c)

Institutions and by the Rest of the World amounted to 1.75 and 1.05 trillion euros, respectively. Considering that the institutional sector Monetary Financial Institutions includes the Eurosystem, the fact that Monetary Financial Institutions and General Governments play a key role on the asset and liability side of the security market is in general not surprising. In fact, until June 2017, within the APP, the Eurosystem carried out public sector security purchases amounting to about 1.64 trillion euros, out of the total asset purchases amounting to about 1.99 trillion euros (European Central Bank 2017b). Moreover, the expectation of the public security purchases by the Eurosystem and the subsequent increase in the price of the purchased securities ${ }^{27}$

\footnotetext{
${ }^{27}$ In particular, there is clear empirical evidence supporting the fact that the pure announcement of unconventional monetary policy in the euro area has been successful in lowering spreads of sovereign bonds issued by peripheral Eurozone's countries (i.e., Greece, Ireland, Italy, Portugal, and Spain), thereby increasing their prices (Acharya et al. 2018). More specifically, this empirical evidence on the signalling effectiveness of unconventional monetary policy is especially associated with the popular "whatever-ittakes speech", delivered by the President of the European Central Bank Mario Draghi on July 26th, 2012, and is particularly strong with reference to Italian and Spanish government bond yields (which recorded a decrease by about two percentage points) (Altavilla et al. 2014; Krishnamurthy et al. 2017; Szczerbowicz and et al 2015).
} 
may have encouraged a rise in the purchases of sovereign securities by Monetary Financial Institutions excluding the Eurosystem.

Concerning the equity layer, represented in Fig. 7, it is worth mentioning that, due to the lack of data on mutual interactions among the euro area institutional sectors and the rest of the world via unlisted equity, it has been possible to map only the mutual financial exposures via listed and investment funds' shares. As represented in Fig. 7, at the end of June 2017, Monetary Financial Institutions did not exhibit large exposures in terms of listed and investment funds' shares and other equity. However, for the purposes of our investigation, it is worth focusing on the Households' exposures in terms of listed and investment funds' shares. In fact, the Households sector exhibits an exposure in terms of Non-MMF Investment Funds' shares amounting to 2.19 trillion euros and in terms of Non-Financial Corporations' listed shares amounting to 0.67 trillion euros. On the one hand, this appeal for the equity market may have arisen from QE, which could have indirectly generated an increase in stock values, making equity investments more attractive. In fact, despite the difficulties in determining the extent and the channel through which equity prices may increase as a consequence of QE, this phenomenon is in line with multiple explanations, which are consistent with the QE transmission channels discussed in the recent literature (e.g., Joyce et al. 2011; Grosse-Rueschkamp et al. 2017). More specifically, first, stock markets may rise as a consequence of an increased market confidence, based on the expectation that the economy will be healthier after the central banks' expansionary intervention (i.e., the confidence channel). In fact, it is generally known that stock markets tend to respond to news on central bank activities, in particular, positively reacting to expansionary policies (i.e., the policy signalling channel). Second, QE may have determined an increased appeal for riskier investments, such as equity investments, by investors seeking higher returns, compared to the decreased returns of the securities purchased within the large-scale programs, thereby increasing stock prices (i.e., the portfolio balance channel). Third, the lower cost of borrowing, as a consequence of QE, may have created an incentive for companies to expand their business (i.e., bank lending channel), providing a signal to market participants of healthy operations and a positive outlook on future demand, pushing up stock markets (i.e., the confidence channel). On the other hand, this result on Households' financial exposures in terms of listed and investment funds' shares could be interpreted as concerning for two main reasons. First, the larger fraction of Households' investment in the financial sector compared to the real sector seems to suggest the Households' preference for investments in financial services rather than in non-financial goods and services. This is consistent with the process of financialization, according to which a large fraction of resources is addressed to finance that mainly funds the purchase of assets that already exist, rather than to businesses that can employ them in financing new capital investment (Turner 2017). Second, although our dataset does not allow us to disaggregate the Households sector at a micro level nor to break it down by level of income or wealth, common knowledge suggests that the fraction of households generally holding financial assets belongs to the rich shares of the population. If so, the potential beneficial effect on asset values arising from QE may generate a flow of resources towards the rich shares of the population, further increasing the gap existing between rich and poor. As a consequence, if the latter resources are not going to 
trickle down to the rest of the population, QE may have concerning implications in terms of inequality.

With regard to the insurance and pension scheme market, it is worth mentioning that available data on insurance and pension schemes include only the breakdown of total holdings and issuances of this financial instrument for every institutional sector. Thus, data on interactions among the institutional sectors via this financial instrument are not available. However, since insurance and pension schemes represent a nonnegligible portion of assets of some institutional sectors (e.g., Households), we have reconstructed these data by assuming that exposures of institutional sectors through insurance and pension schemes are proportional to the breakdown of total holdings and issuances of the same instrument. As shown in Fig. 8, at the end of June 2017, Monetary Financial Institutions did not exhibit large exposures in terms of insurance and pension schemes. Indeed, on the one hand, the largest fraction of insurance and pension schemes is held by Households (7.8 trillion euros), followed by Rest of the World (0.36 trillion euros), Insurance Corporations and Pension Funds (0.29 trillion euros), and Non-Financial Corporations (0.17 trillion euros). On the other hand, insurance and pension schemes are mostly issued by Insurance Corporations and Pension Funds (8.27 trillion euros), followed by Non-Financial Corporations (0.35 trillion euros).

Lastly, Fig. 9 provides us with a comprehensive picture of the outstanding financial exposures among the different institutional sectors operating in the euro area and the rest of the world across the considered financial instruments, prior to and after the implementation of QE. The comprehensive analysis of the euro area economy as a multilayer macro-network allows us to obtain further insights on the challenging problem of estimating the financial interdependencies existing between the banking sector and both the real and the financial sectors. Indeed, it enables the consideration of the relevant indirect exposures via the different financial instruments considered together (Perillo and Battiston 2018). Further, this analysis provides us with a map of the potential channels through which distress may propagate as a consequence of shocks of different nature (Perillo and Battiston 2018). As shown in Perillo and Battiston (2018), both the insights on the estimate of financial interdependencies and the map of the potential distress propagation channels could not be obtained with a single layer analysis. Differently from Figs. 5-8, in Fig. 9 we compute weights as percentages of the total financial assets of the source institutional sectors, in order to make the different layers of the multilayer macro-network more homogeneous. Moreover, for the sake of clarity, we remove links with a weight below $10 \%$. In this way, by focusing on the most relevant links connecting the different institutional sectors of the euro area via loans and deposits, debt securities, equity, and insurance and pension schemes, we can easily identify the existence of the banking system's indirect exposures.

In particular, with reference to 2014Q3, as shown in Fig. 9a, Monetary Financial Institutions exhibited a direct exposure amounting to about $16 \%$ of their total financial assets to Households, via loans and deposits. In turn, Households, other than being exposed to Monetary Financial Institutions for about 29\% of their total financial assets via loans and deposits, were exposed for about $31 \%$ of their total financial assets to Insurance Corporations and Pension Funds via insurance and 
pension schemes. The chain may continue i) via debt securities to General Governments and via loans and deposits to Monetary Financial Institutions. Further, from Insurance Corporations and Pension Funds, it may also continue ii) via equity to Non-MMF Investment Funds, arriving to the Rest of the World both via equity and debt securities (and possibly coming back to Non-MMF Investment Funds via equity, restarting this small loop), coming back to Monetary Financial Institutions via loans and deposits. An alternative path from Rest of the World may also involve coming back to General Governments via debt securities and via loans and deposits to Monetary Financial Institutions. Since in all three cases the paths end with Monetary Financial Institutions, which was also the starting point of the chain, it may be possible that the chain restarts from the beginning and enters in a loop. These findings shed light on the existence of indirect exposures of the banking system to the financial sector, and, in particular, to Insurance Corporations and Pension Funds and NonMMF Investment Funds. The latter exposures could not be identified if the euro area economy was not regarded as a multilayer financial network, leading to an underestimation of the exposures of the banking sector to the financial sector and the potential associated risks. In the same line, with reference to 2017Q2, as shown in Fig. 9b, it is possible to identify a very similar path through which distress may propagate as

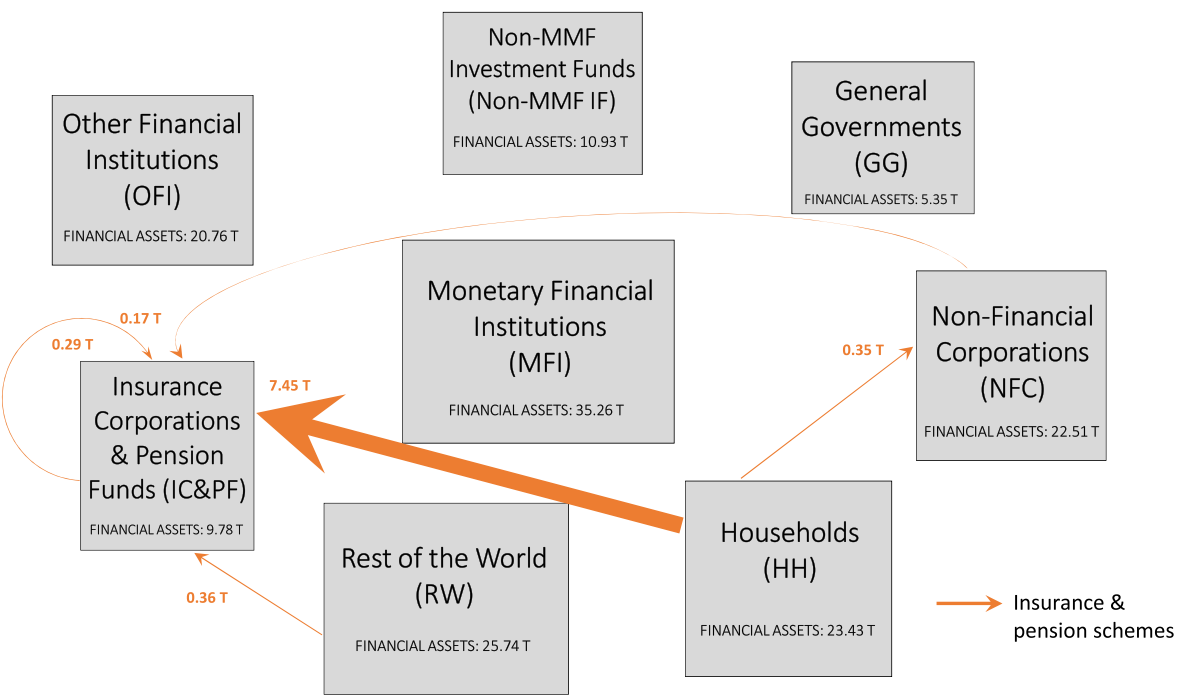

Fig. 8 The euro area macro-network of financial exposures via insurance and pension schemes; June 2017. The macro-network of financial exposures among the different institutional sectors operating in the euro area (i.e., Monetary Financial Institutions (MFI), Other Financial Institutions (OFI), Non-MMF Investment Funds (Non-MMF IF), Insurance Corporations and Pension Funds (IC\&PF), Households (HH), Non-Financial Corporations (NFC), and General Governments $(G G)$ ), and Rest of the World (RW), via insurance and pension schemes (represented with orange links), with reference to the second quarter of 2017. Weights represent the outstanding financial exposures via insurance and pension schemes of a source institutional sector to a target institutional sector and they are expressed in trillion euros. Links with a weight below $1 \%$ of total insurance and pension schemes held and issued by the aforementioned institutional sectors have been removed. Source: authors' computations based on (European Central Bank 2017c) 


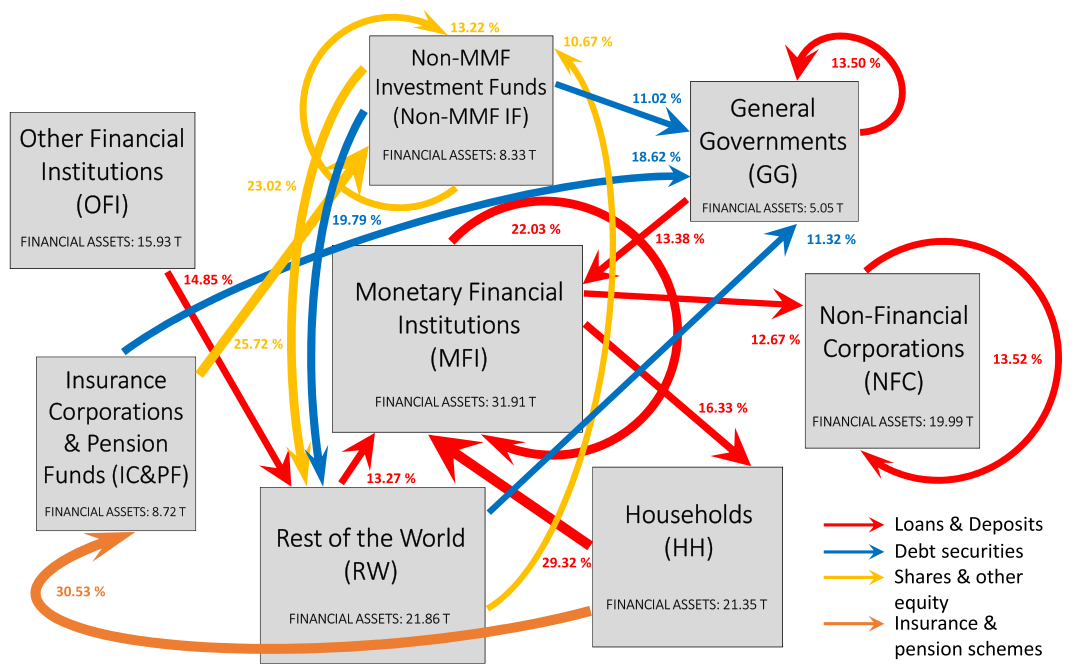

(a)

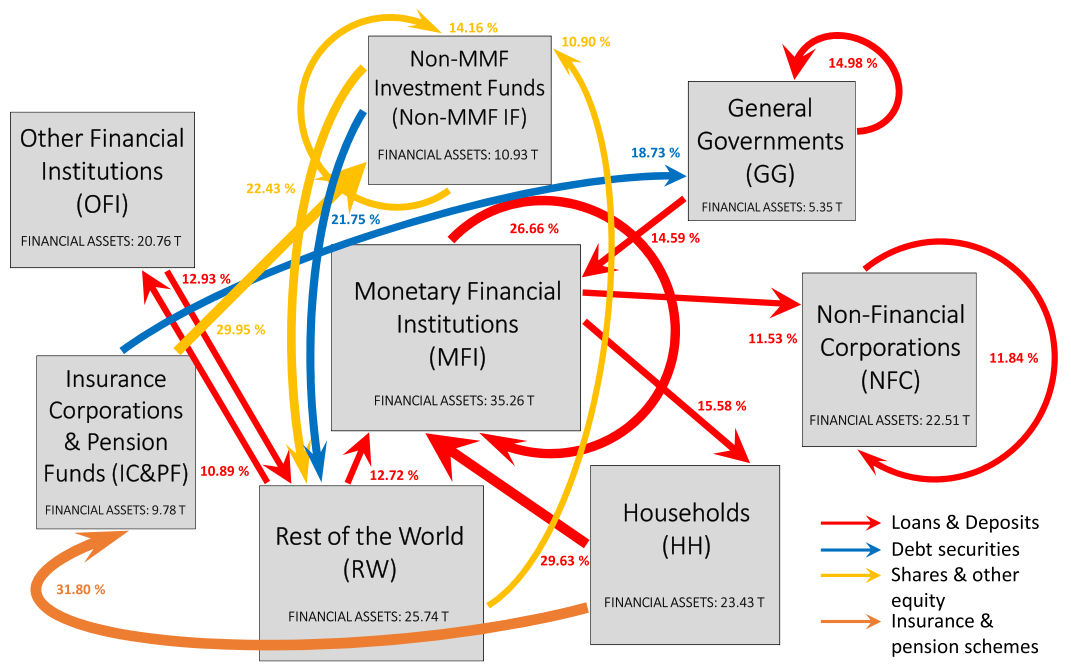

(b)

Fig. 9 The multilayer macro-network of financial exposures in the euro area; (a) September 2014 (b) June 2017. Multilayer macro-network of financial exposures among the different institutional sectors operating in the euro area (i.e., Monetary Financial Institutions (MFI), Other Financial Institutions (OFI), Non-MMF Investment Funds (Non-MMF IF), Insurance Corporations and Pension Funds (IC\&PF), Households (HH), Non-Financial Corporations (NFC), and General Governments $(G G)$ ), and the Rest of the World ( $R W$ ), via i) loans and deposits (red links), ii) private and public securities (blue links), iii) shares and other equity (yellow links), and iv) insurance and pension schemes (orange links). Weights represent the outstanding financial exposures of a source institutional sector to a target institutional sector and they are normalized by total assets of the source. Links with a weight below $10 \%$ of the source institutional sector's total assets have been removed. Source: authors' computations based on (European Central Bank 2017c) 
Table 1 Network statistics - multilayer macro-network 2014Q3

\begin{tabular}{lllllll}
\hline Institutional sectors & $C_{D-\text { out }}^{w \alpha}$ & $C_{D-i n}^{w \alpha}$ & $C_{C}^{w \alpha}$ & $C_{B}^{w \alpha}$ & $C_{K}^{w}$ & $h_{i}(t+1)$ \\
\hline Non-Financial Corporations & 8.074 & 11.123 & 0.120 & 0 & 635.849 & 0.155 \\
Monetary Financial Institutions & 15.159 & 14.917 & 0.217 & 21 & 1132.908 & 0.226 \\
Non-MMF Investment Funds & 8.012 & 8.151 & 0.128 & 0 & 196.779 & 0.235 \\
Other Financial Institutions & 8.323 & 8.199 & 0.135 & 0 & 319.374 & 0.175 \\
Insurance Corporations and Pension Funds & 8.066 & 7.962 & 0.139 & 0 & 205.344 & 0.233 \\
General Governments & 4.750 & 9.517 & 0.085 & 0 & 449.839 & 0.177 \\
Households & 11.744 & 6.988 & 0.192 & 6 & 394.711 & 0.220 \\
Rest of the World & 11.594 & 10.282 & 0.200 & 10 & 460.217 & 0.207 \\
\hline
\end{tabular}

a consequence of shocks of different nature. More specifically, at the end of June 2017 and similarly to the end of September 2014, Monetary Financial Institutions exhibit a direct exposure amounting to about $16 \%$ of their total financial assets to Households, via loans and deposits. In turn, Households, other than being exposed to Monetary Financial Institutions for about $30 \%$ of their total financial assets via loans and deposits, are exposed for about $32 \%$ of their total financial assets to Insurance Corporations and Pension Funds via insurance and pension schemes. The chain may continue i) via debt securities to General Governments and via loans and deposits to Monetary Financial Institutions. Further, from Insurance Corporations and Pension Funds, it may also continue ii) via equity to Non-MMF Investment Funds arriving to the Rest of the World both via equity and debt securities (and possibly coming back to Non-MMF Investment Funds via equity, restarting this small loop), coming back to Monetary Financial Institutions via loans and deposits. Similarly to the case of 2014Q3, since both paths end with Monetary Financial Institutions, which was also the starting point of the chain, it may be possible that the chain restarts from the beginning and enters in a loop.

Tables 1 and 2 report some network statistics (see Section 2.2) computed on the multilayer macro-networks of financial exposures with reference to 2014Q3 and 2017Q2. In particular, we have computed the generalized version of the degree,

Table 2 Network statistics - multilayer macro-network 2017Q2

\begin{tabular}{lllllll}
\hline Institutional sectors & $C_{D-\text { out }}^{w \alpha}$ & $C_{D-i n}^{w \alpha}$ & $C_{C}^{w \alpha}$ & $C_{B}^{w \alpha}$ & $C_{K}^{w}$ & $h_{i}(t+1)$ \\
\hline Non-Financial Corporations & 8.474 & 11.822 & 0.129 & 0 & 504.524 & 0.154 \\
Monetary Financial Institutions & 16.173 & 15.788 & 0.227 & 19 & 988.013 & 0.231 \\
Non-MMF Investment Funds & 9.027 & 9.282 & 0.139 & 0 & 178.298 & 0.230 \\
Other Financial Institutions & 8.808 & 8.810 & 0.139 & 0 & 262.804 & 0.164 \\
Insurance Corporations and Pension Funds & 8.511 & 8.488 & 0.143 & 0 & 161.171 & 0.232 \\
General Governments & 4.917 & 9.711 & 0.089 & 0 & 363.680 & 0.178 \\
Households & 12.366 & 7.135 & 0.201 & 6 & 312.152 & 0.222 \\
Rest of the World & 12.458 & 11.275 & 0.211 & 11 & 393.715 & 0.204 \\
\hline
\end{tabular}


closeness, and betweenness centrality measures defined in Eq. 2-6, after setting the tuning parameter $\alpha$ equal to 0.5 . Further, we have calculated the Katz centrality given by Eq. 7, and a measure of nodes' vulnerability coming from the generalized version of DebtRank defined by Eq. 8. In Eq. 8, we have set the initial shock equal to 0.1 and the recovery rate equal to its conventional value of 0.6. Moreover, since three of the institutional sectors under consideration exhibit a negative equity, we have computed Eq. 8, by replacing the leverage matrix with the matrix of financial exposures through which the different institutional sectors are tied to each other relative to total financial assets of the source institutional sector (Castrén and Rancan 2014). As shown in Tables 1 and 2, Monetary Financial Institutions exhibit the highest centrality according to all the centrality measures that we have computed, i.e., out-degree, in-degree, closeness, betweenness, and Katz centrality measures, both prior to and after the implementation of Quantitative Easing. Moreover, according to the generalized DebtRank distress propagation process, on the one hand, Non-MMF Investment Funds and Insurance Corporations and Pension Funds exhibit the highest vulnerability in the pre-QE multilayer macro-network of financial exposures. On the other hand, Insurance Corporations and Pension Funds, Monetary Financial Institutions, and Non-MMF Investment Funds seem to be the most vulnerable nodes in the post-QE multilayer macro-network of financial exposures. Further, a comparison of nodes' vulnerability between the pre- and post-QE multilayer macro-networks suggests that, since the implementation of this policy, on the one hand, Non-MMF Investment Funds' and Other Financial Institutions' vulnerability has decreased. Moreover, Non-Financial Corporations', Insurance Corporations and Pension Funds', and Rest of the World's vulnerability has slightly decreased. On the other hand, since the implementation of QE, Monetary Financial Institutions' vulnerability has increased, while General Governments' and Households' vulnerability has slightly increased.

\subsection{Financialization of the euro area economy}

\subsubsection{The static perspective}

In an attempt to investigate the phenomenon of financialization in the euro area, we first compute some static measures that could provide us with evidence about the importance of the role played by finance in the euro area. Indeed, first, based on the multilayer macro-network of financial exposures, we derive the breakdown of euro area financial institutions' assets by counterparty macro sector. In particular, we distinguish financial institutions' assets among intra-financial, financial-real, financial-public, financial-world, and financial-unspecified assets, depending on whether the counterparty belongs to the financial, real, public, non-euro area, or unspecified macro sector, respectively. More specifically, the residual category "financial-unspecified" includes all the financial assets held by the financial sector the counterparty of which is unspecified. Figure 10 illustrates the breakdown of euro area financial institutions' assets by counterparty macro sector, with reference to the second quarter of 2017. As can be seen from Fig. 10, the largest portion of financial institutions' assets is intra-financial (33\% of financial institutions' assets), 


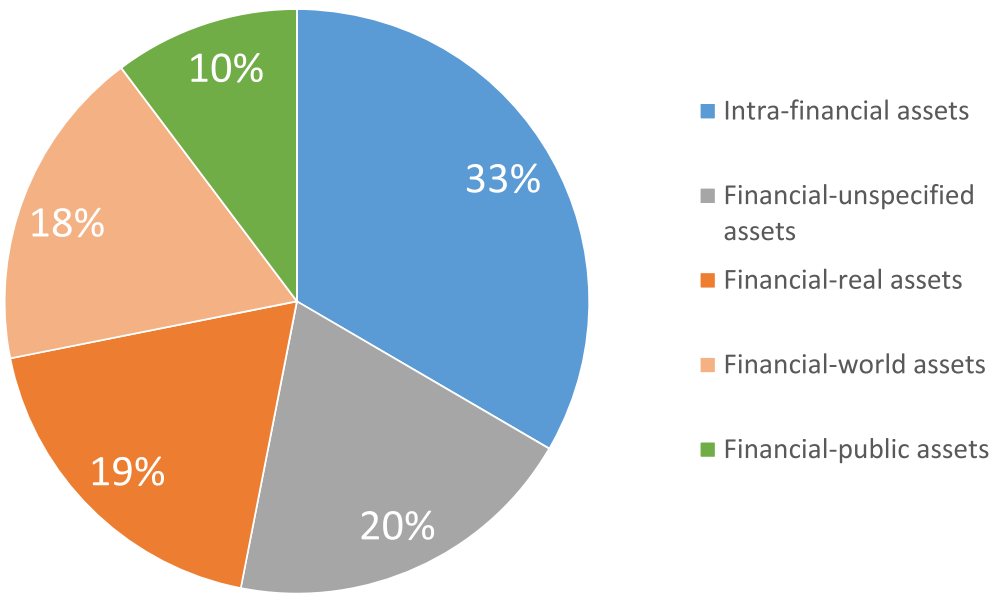

Fig. 10 Breakdown of euro area financial institutions' assets by counterparty macro sector; June 2017. Breakdown of euro area financial sector's (i.e., Monetary Financial Institutions, Other Financial Institutions, Non-MMF Investment Funds, and Insurance Corporations and Pension Funds) assets by counterparty macro sector, i.e., financial sector (including all the aforementioned financial institutions, in light blue), real sector (including Households and Non-Financial Corporations, in orange), public sector (including General Governments, in light green), rest of the world (in pink), and unspecified (in grey), with reference to the second quarter of 2017. The residual category "financial-unspecified assets" includes the financial sector's assets the counterparty of which is unspecified. Source: authors' computations based on (European Central Bank 2017c)

followed by financial-real assets (19\% of financial institutions' assets), financialworld assets (18\% of financial institutions' assets), and financial-public assets (10\% of financial institutions' assets). It is worth mentioning that the assets for which we are not able to identify the counterparty macro sector based on available data amount to $20 \%$ of financial institutions' assets. Moreover, unfortunately, our dataset does not allow us to disaggregate the financial-world financial institutions' assets by counterparty sector operating in the non-euro area countries. However, broadly speaking, the breakdown of the euro area financial institutions' assets by counterparty macro sector provides us with empirical evidence about the fact that a very large fraction of the financial sector's business is intra-financial.

Second, we compute the breakdown of the euro area financial institutions' assets by holder and counterparty macro sector (represented in Fig. 11). As we can see from Fig. 11, Monetary Financial Institutions and Insurance Corporations and Pension Funds mainly interact with the financial sector. In fact, Monetary Financial Institutions hold intra-financial assets amounting to 13.99 trillion euros, followed by financial-real assets amounting to 9.90 trillion euros, while Insurance Corporations and Pension Funds are exposed to the financial sector for 4.92 trillion euros and to the public sector for 1.94 trillion euros. As regards Other Financial Institutions, they are largely exposed to the residual category unspecified (for 11.07 trillion euros) and to the financial sector (for 3.57 trillion euros). Lastly, Non-MMF Investment Funds mainly interact with the Rest of the World (with an exposure to non-euro area countries amounting to 4.87 trillion euros) and with the financial sector (with an exposure 


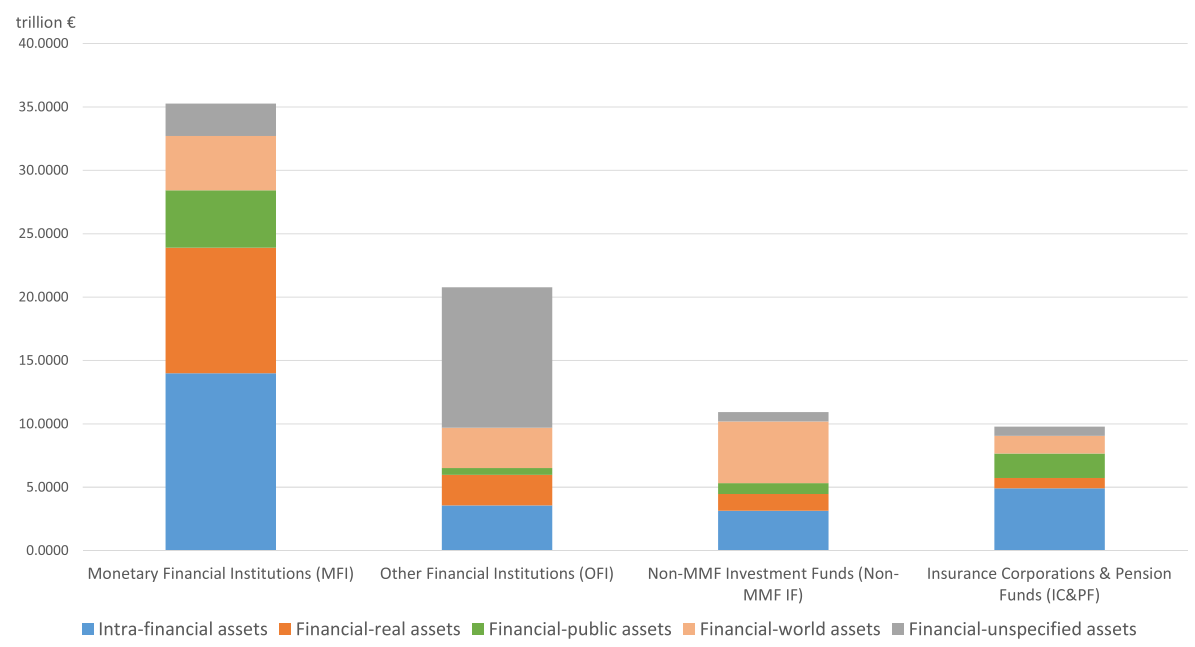

Fig. 11 Breakdown of euro area financial institutions' assets by holder and counterparty macro sector; June 2017. Breakdown of euro area financial institutions' assets by holder (i.e., Monetary Financial Institutions, Other Financial Institutions, Non-MMF Investment Funds, and Insurance Corporations and Pension Funds) and counterparty macro sector, i.e., financial sector (including all the aforementioned financial institutions, in light blue), real sector (including Households and Non-Financial Corporations, in orange), public sector (including General Governments, in light green), rest of the world (in pink), and unspecified (in grey), with reference to the second quarter of 2017. The residual category "financialunspecified assets" includes the financial sector's assets the counterparty of which is unspecified. Source: authors' computations based on (European Central Bank 2017c)

to financial institutions equal to 3.15 trillion euros). As a consequence, the breakdown of euro area financial institutions' assets by holder and counterparty macro sector confirms that financial institutions largely interact with one another.

Lastly, we compute the breakdown of financial institutions' i) loans and deposits (represented in Fig. 12), ii) bonds (represented in Fig. 13), and iii) equity (represented in Fig. 14), by holder and counterparty macro sector. These breakdowns provide us with further empirical evidence about the importance played by the financial sector in the euro area economy. In fact, Figs. 12 and 14 show that loans and deposits, and shares and other equity are mainly intra-financial. With reference to bonds, as we can see from Fig. 13, financial institutions are mainly exposed to the public sector. This is consistent with the fact that, out of the total asset purchases carried out by the Eurosystem until June 2017 within QE, approximatively the $82 \%$ were public sector securities.

\subsubsection{The dynamic perspective}

The static measures of financialization have provided us with empirical evidence about the large importance of the role played by finance in the euro area. However, these measures can only capture the current role of financialization in the euro area. Therefore, in order to explore the transmission of resources to the real economy and the evolution of the process of financialization since the implementation 


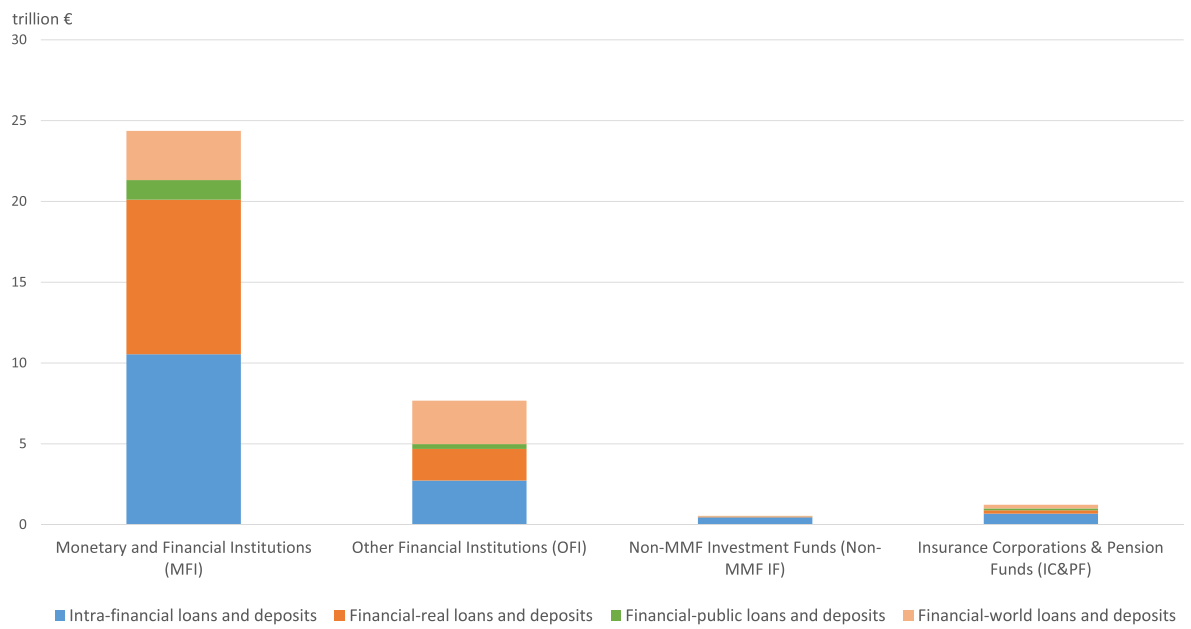

Fig. 12 Breakdown of euro area financial institutions' loans and deposits by creditor and counterparty macro sector; June 2017. Breakdown of euro area financial institutions' loans and deposits by creditor (i.e., Monetary Financial Institutions, Other Financial Institutions, Non-MMF Investment Funds, and Insurance Corporations and Pension Funds) and counterparty macro sector, i.e., financial sector (including all the aforementioned financial institutions, in light blue), real sector (including Households and Non-Financial Corporations, in orange), public sector (including General Governments, in light green), and rest of the world (in pink), with reference to the second quarter of 2017. Source: authors' computations based on (European Central Bank 2017c)

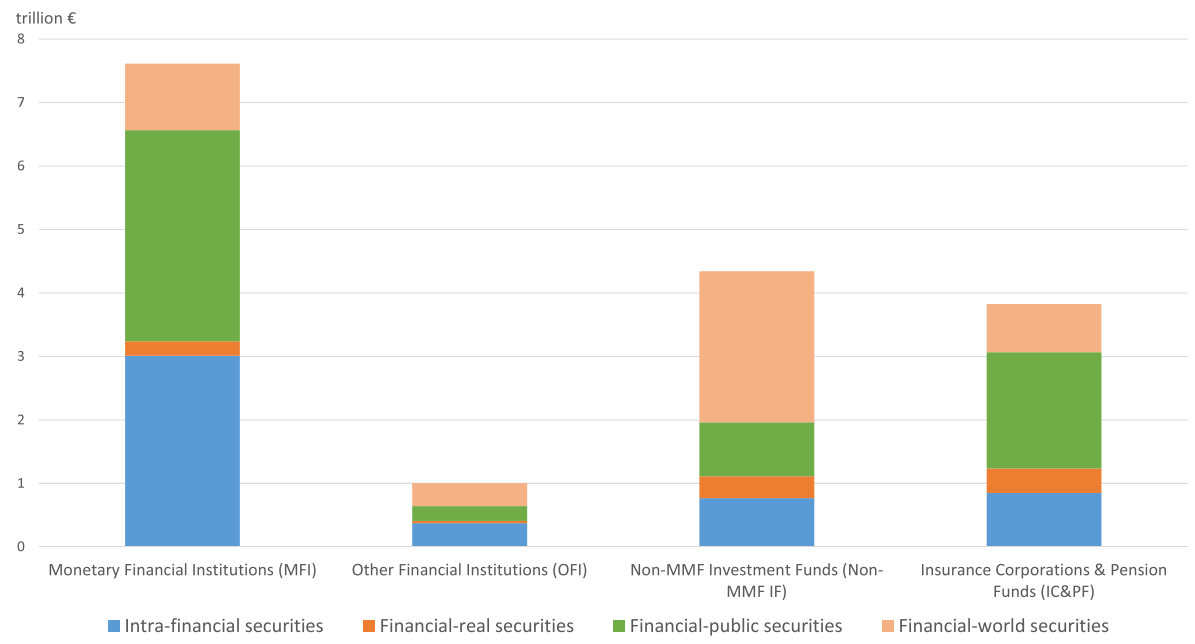

Fig. 13 Breakdown of euro area financial institutions' debt securities by holder and counterparty macro sector; June 2017. Breakdown of euro area financial institutions' debt securities by holder (i.e., Monetary Financial Institutions, Other Financial Institutions, Non-MMF Investment Funds, and Insurance Corporations and Pension Funds) and counterparty macro sector, i.e., financial sector (including all the aforementioned financial institutions, in light blue), real sector (including Households and Non-Financial Corporations, in orange), public sector (including General Governments, in light green), and rest of the world (in pink), with reference to the second quarter of 2017. Source: authors' computations based on (European Central Bank 2017c) 


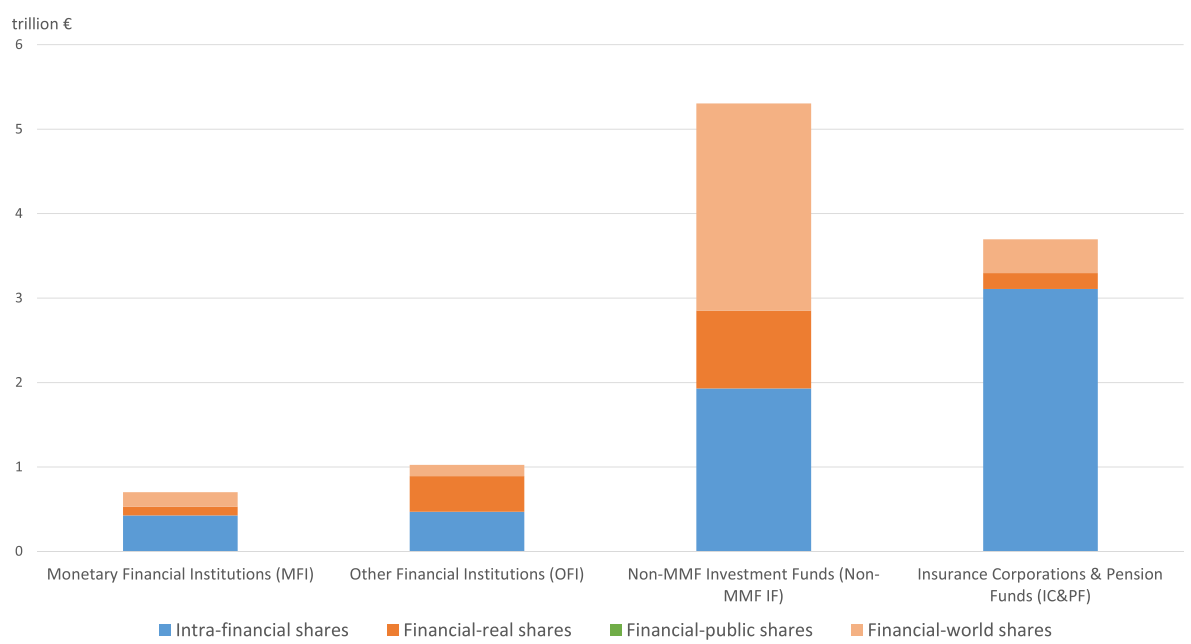

Fig. 14 Breakdown of euro area financial institutions' shares and other equity by holder and counterparty macro sector; June 2017. Breakdown of euro area financial institutions' shares and other equity by holder (i.e., Monetary Financial Institutions, Other Financial Institutions, Non-MMF Investment Funds, and Insurance Corporations and Pension Funds) and counterparty macro sector, i.e., financial sector (including all the aforementioned financial institutions, in light blue), real sector (including Households and Non-Financial Corporations, in orange), public sector (including General Governments, in light green), and rest of the world (in pink), with reference to the second quarter of 2017. Source: authors' computations based on (European Central Bank 2017c)

of QE, we compute some dynamic indicators. In particular, building on the existing literature on financialization, we first compute some standard indicators able to capture the process of financialization of the euro area over time. These standard indicators are the ratio of financial assets to GDP (represented in Fig. 15) and the ratio of bank assets to GDP (represented in Fig. 16). More specifically, on the one hand, Fig. 15 represents the time evolution of the ratio of financial assets held by the institutional sectors operating in the euro area (i.e., Monetary Financial Institutions, Other Financial Institutions, Non-MMF Investment Funds, Insurance Corporations and Pension Funds, Households, Non-Financial Corporations, and General Governments) to GDP over the reference period 2012Q4-2017Q2. On the other hand, Fig. 16 represents the time series of the ratio of financial assets held by the euro area Monetary Financial Institutions to GDP over the reference period 2012Q4-2017Q2. The vertical dashed line corresponds to the beginning of the first purchase program included in the APP, started in the fourth quarter of 2014. We estimated the growth rate of the ratio of euro area financial assets to GDP, as well as the growth rate of the ratio of euro area bank assets to GDP (reported on the right-hand side of Figs. 15 and 16), since the implementation of QE. As we can see from the two pictures, since QE, the ratio of euro area financial assets to GDP increased by $8.72 \%$ and the ratio of euro area bank assets to GDP increased by $6.23 \%$. Consequently, the empirical evidence provided by the two standard measures used in the literature to capture the process of financialization suggests that, since $\mathrm{QE}$, there has been an increase in the importance of the role played by finance in the euro area economy. 


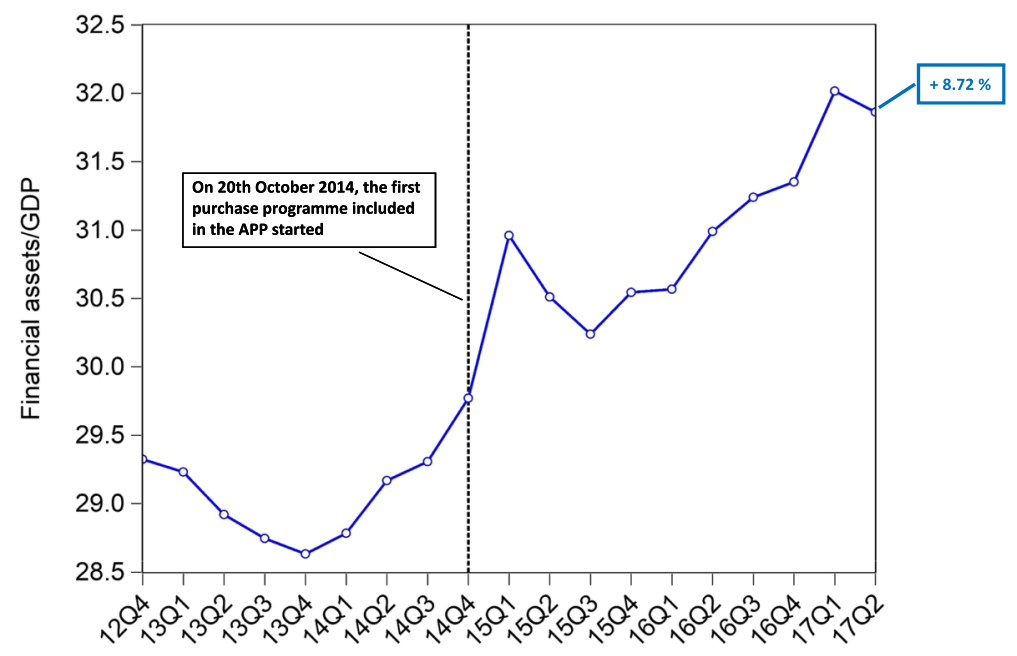

Time

Fig. 15 Ratio of euro area financial assets to GDP; 2012Q4-2017Q2. Time series of the ratio of financial assets (including loans and deposits, private and public securities, and listed and investment fund shares) held by the institutional sectors operating in the euro area (i.e., Monetary Financial Institutions, Other Financial Institutions, Non-MMF Investment Funds, Insurance Corporations and Pension Funds, Households, Non-Financial Corporations, and General Governments) to GDP, over the reference period 2012Q4-2017Q2. The vertical dashed line corresponds to the beginning of the first purchase program (3rd Covered Bond Purchase Programme, CBPP3) included in the APP, started in 2014Q4, while the percentage on the right-hand side of the graph corresponds to our estimate of the growth rate of the ratio of euro area financial assets to GDP, since the initiation of QE. Source: authors' computations based on (European Central Bank 2017c)

We then investigate the effect of the implementation of QE on the time evolution of the financial linkages in the multilayer macro-network of the euro area. In particular, we explore the time evolution of the breakdown of the euro area financial system's assets by counterparty macro sector (Fig. 17) over the reference period 2013Q4-2017Q2. Further, we investigate the time evolution of the breakdown of the euro area financial system's loans and deposits (Fig. 18), private and public securities (Fig. 19), and shares and other equity (Fig. 20) by counterparty macro sector, over the same reference period. Our main focus is on the fraction of intra-financial loans, securities and equity (represented in light blue) compared to the fraction of financialreal loans, securities and equity (represented in orange) for two main reasons. First, these measures enable us to investigate the transmission of resources to the real economy through the increase in the interactions between the financial sector and the real sector, via loans and deposits, securities, and equity, since the implementation of QE. Second, these indicators allow us to investigate the process of financialization of the euro area through the increase in intra-financial interactions via loans and deposits, securities, and equity, since the implementation of $\mathrm{QE}$. As before, the vertical dashed line corresponds to the beginning of the first purchase program included in the APP, started in the fourth quarter of 2014, and the percentages on the right-hand 


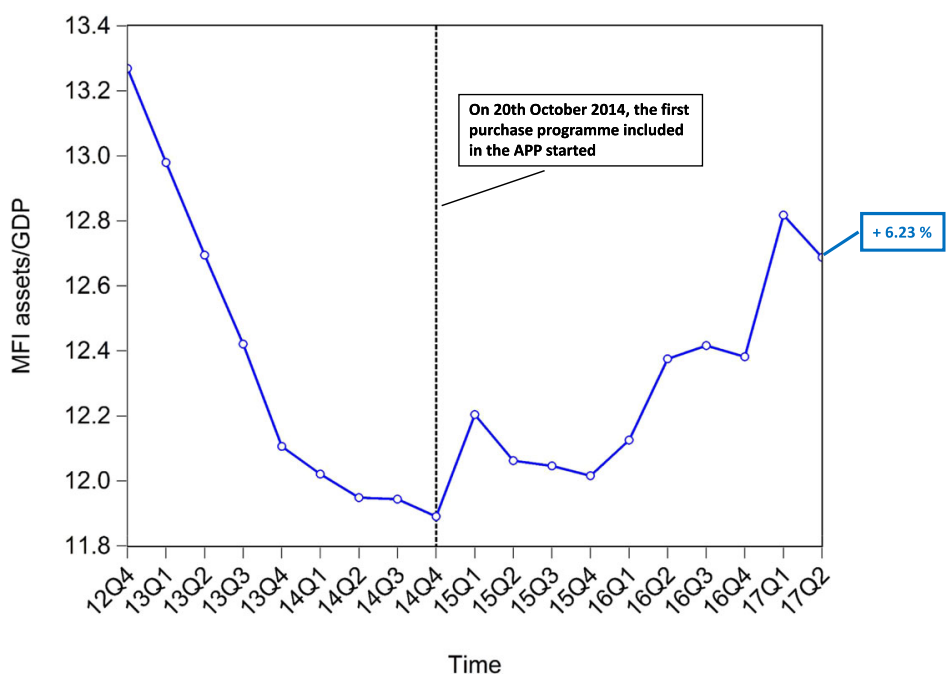

Fig. 16 Ratio of euro area bank assets to GDP; 2012Q4-2017Q2. Time series of the ratio of financial assets (including loans and deposits, private and public securities, and listed and investment fund shares) held by Monetary Financial Institutions operating in the euro area to GDP, over the reference period 2012Q42017Q2. The vertical dashed line corresponds to the beginning of the first purchase program (3rd Covered Bond Purchase Programme, CBPP3) included in the APP, started in 2014Q4, while the percentage on the right-hand side of the graph corresponds to our estimate of the growth rate of the ratio of euro area bank assets to GDP, since the initiation of QE. Source: authors' computations based on (European Central Bank 2017c)

side of Figs. 17-20 correspond to our estimates of the growth rate of intra-financial interactions versus financial-real interactions. As we can see from Fig. 17, since QE, intra-financial interactions have increased by $18.19 \%$, while the interactions between financial system and real economy grew by $8.09 \%$. More specifically, on the one hand, since QE, intra-financial loans and deposits, and shares and other equity have increased by $19.75 \%$ and $35.25 \%$, respectively, while financial-real loans and deposits, and shares and other equity have grown by $4.22 \%$ and $35.36 \%$ (Figs. 18 and 20). On the other hand, intra-financial bonds have decreased by $0.46 \%$, while financial-real bonds have grown by $21.21 \%$ (Fig. 19). Moreover, from Figs. 17-20, it is clear that a major role in the general increase in financial system interactions has been played by the increase in financial system loans and deposits, which, apparently, have been mostly addressed to the financial system itself. As a consequence, the empirical evidence based on our financialization measures, and in particular on the general situation in terms of fraction of intra-financial assets versus financialreal assets, captured by Fig. 17, allows us to state that, since QE, there has been an increase in financial system activities, but mostly addressed to the financial system itself. It is worth mentioning that the aforementioned empirical evidence does not imply a causal link between QE and the increase in intra-financial assets in the euro area economy, but the identification of a temporal relationship between the implementation of QE and the increase in the intra-financial activity. In order to verify the robustness of our exploratory results, we also perform a correlation analysis between 


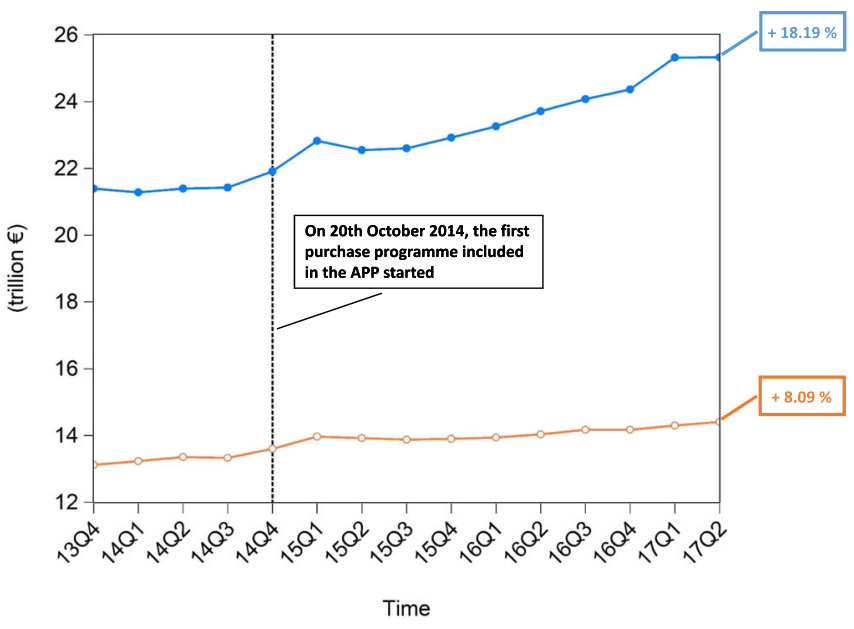

(a)

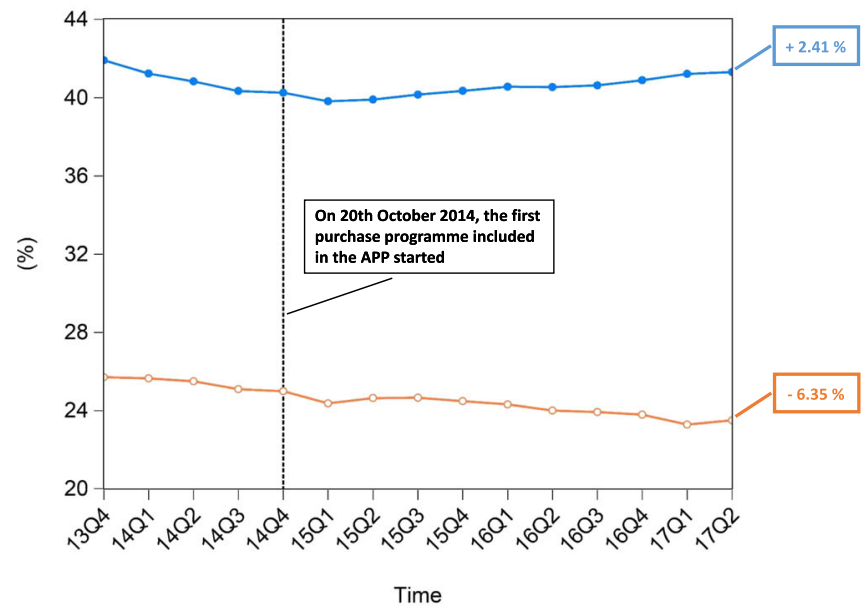

$-\infty$ Financial-real assets Intra-financial assets

(b)

Fig. 17 Breakdown of euro area financial system's assets by counterparty sector - intra-financial versus real exposures; 2013Q4-2017Q2; (a) in trillion euros (b) as a percentage of total financial system's assets. Time series of financial assets (including loans and deposits, private and public securities, and listed and investment fund shares) held by the euro area financial system (including Monetary Financial Institutions, Other Financial Institutions, Non-MMF Investment Funds, and Insurance Corporations and Pension Funds) by counterparty sector, i.e., financial sector (including all the aforementioned financial institutions, in light blue), and real sector (including Households and Non-Financial Corporations, in orange), over the reference period 2013Q4-2017Q2. The vertical dashed line corresponds to the beginning of the first purchase program (3rd Covered Bond Purchase Programme, CBPP3) included in the APP, started in 2014Q4, while the percentages on the right-hand side of the graphs correspond to our estimates of the growth rates of intra-financial and financial-real assets, since the initiation of QE. Source: authors' computations based on (European Central Bank 2017c) 


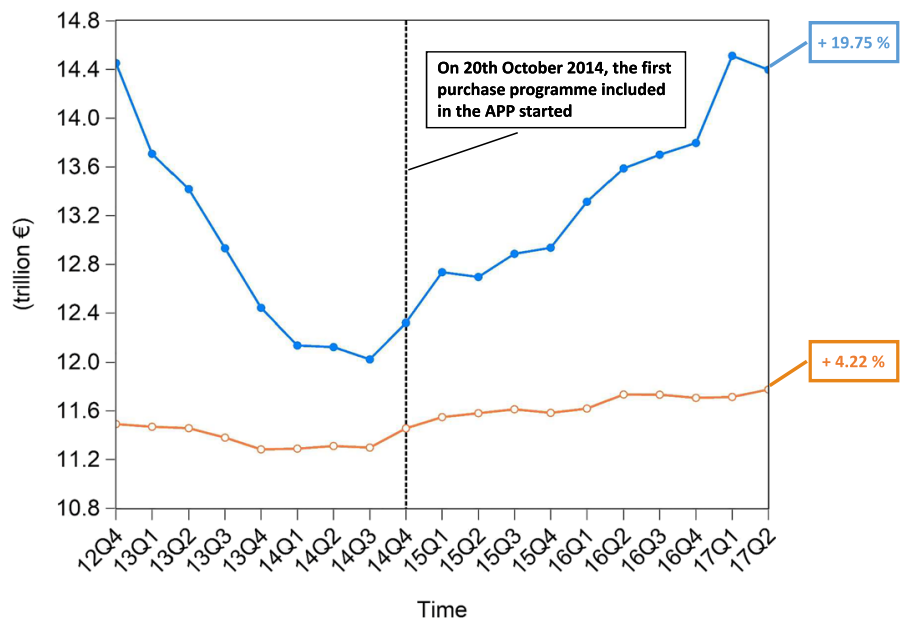

(a)

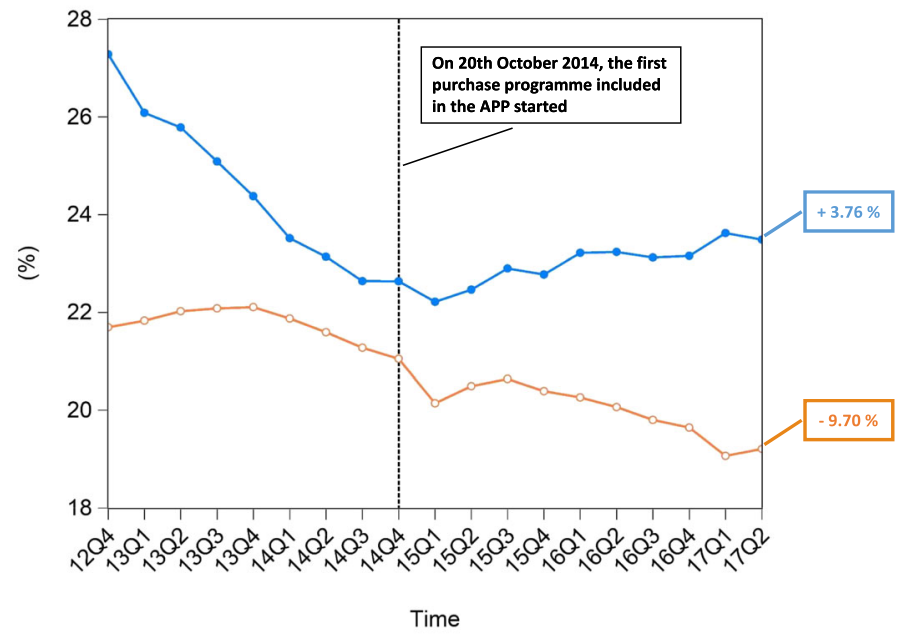

- Intra-financial loans and deposits Financial-real loans and deposits

(b)

Fig. 18 Breakdown of euro area financial system's loans and deposits by counterparty sector - intrafinancial versus real exposures; 2012Q4-2017Q2; (a) in trillion euros (b) as a percentage of total financial system's assets. Time series of loans and deposits granted/held by the euro area financial system (including Monetary Financial Institutions, Other Financial Institutions, Non-MMF Investment Funds, and Insurance Corporations and Pension Funds) by counterparty sector, i.e., financial sector (including all the aforementioned financial institutions, in light blue), and real sector (including Households and Non-Financial Corporations, in orange), over the reference period 2012Q4-2017Q2. The vertical dashed line corresponds to the beginning of the first purchase program (3rd Covered Bond Purchase Programme, CBPP3) included in the APP, started in 2014Q4, while the percentages on the right-hand side of the graphs correspond to our estimates of the growth rates of intra-financial and financial-real loans and deposits, since the initiation of QE. Source: authors' computations based on (European Central Bank 2017c) 


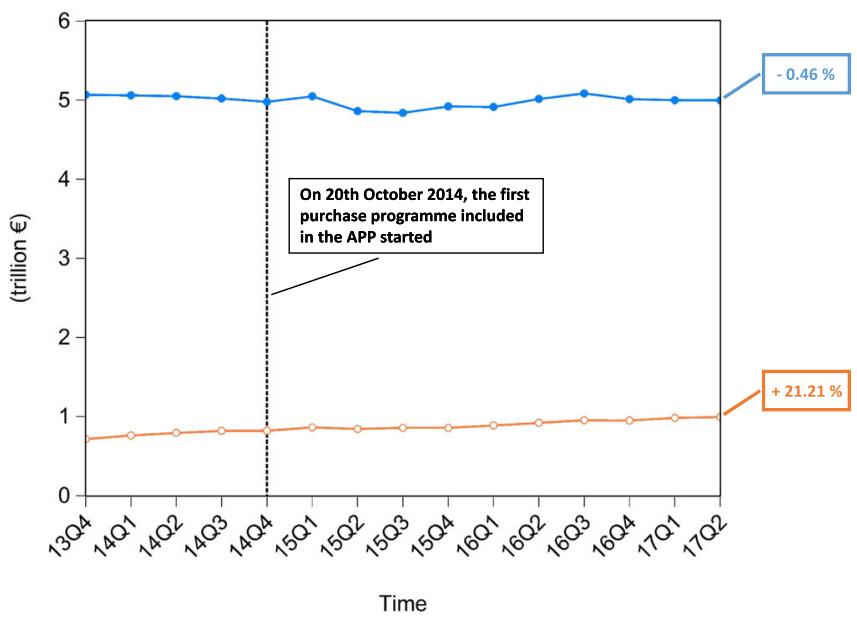

(a)

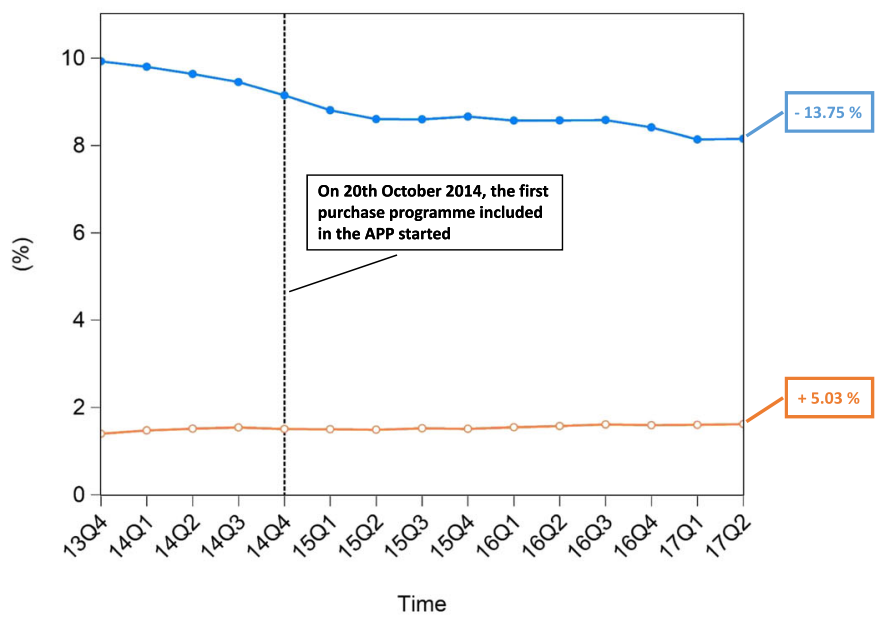

\section{$\rightarrow$ Intra-financial securities Financial-real securities}

(b)

Fig. 19 Breakdown of euro area financial system's debt securities by counterparty sector - intra-financial versus real exposures; 2013Q4-2017Q2; (a) in trillion euros (b) as a percentage of total financial system's assets. Time series of debt securities (including short-term and long-term private and public securities) held by the euro area financial system (including Monetary Financial Institutions, Other Financial Institutions, Non-MMF Investment Funds, and Insurance Corporations and Pension Funds) by counterparty sector, i.e., financial sector (including all the aforementioned financial institutions, in light blue), and real sector (including Households and Non-Financial Corporations, in orange), over the reference period 2013Q4-2017Q2. The vertical dashed line corresponds to the beginning of the first purchase program (3rd Covered Bond Purchase Programme, CBPP3) included in the APP, started in 2014Q4, while the percentages on the right-hand side of the graphs correspond to our estimates of the growth rates of intra-financial and financial-real exposures in terms of debt securities, since the initiation of QE. Source: authors' computations based on (European Central Bank 2017c) 


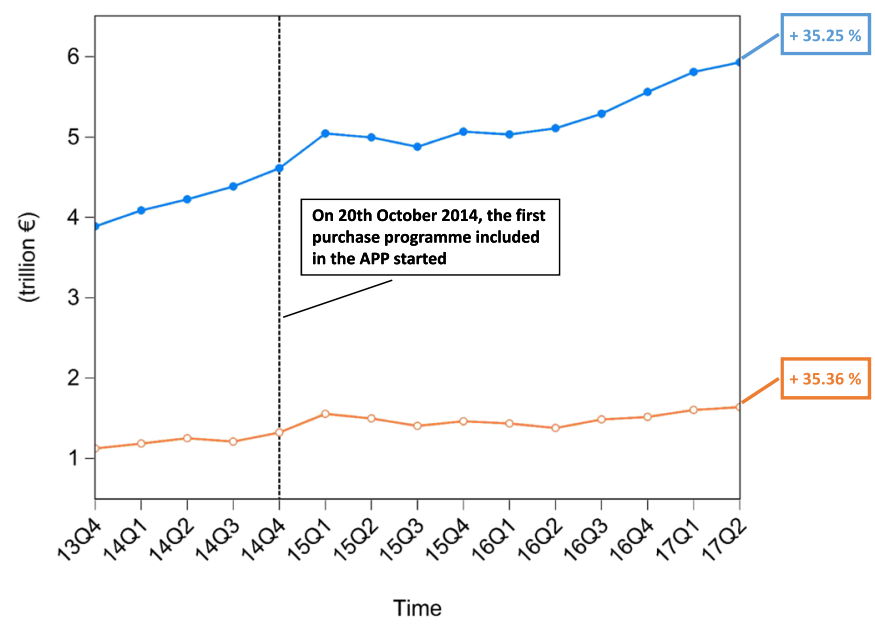

(a)

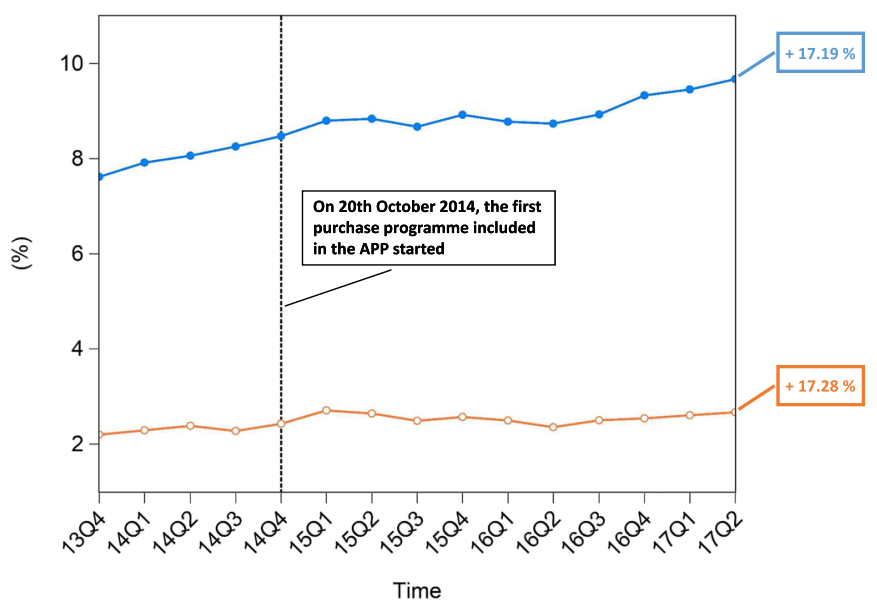

$-\infty$ Financial-real shares

Intra-financial shares

(b)

Fig. 20 Breakdown of euro area financial system's shares and other equity by counterparty sector - intrafinancial versus real exposures; 2013Q4-2017Q2; (a) in trillion euros (b) as a percentage of total financial system's assets. Time series of shares and other equity (including listed and investment fund shares and other equity) held by the euro area financial system (including Monetary Financial Institutions, Other Financial Institutions, Non-MMF Investment Funds, and Insurance Corporations and Pension Funds) by counterparty sector, i.e., financial sector (including all the aforementioned financial institutions, in light blue), and real sector (including Households and Non-Financial Corporations, in orange), over the reference period 2013Q4-2017Q2. The vertical dashed line corresponds to the beginning of the first purchase program (3rd Covered Bond Purchase Programme, CBPP3) included in the APP, started in 2014Q4, while the percentages on the right-hand side of the graphs correspond to our estimates of the growth rates of intra-financial and financial-real exposures in terms of shares and other equity, since the initiation of QE. Source: authors' computations based on (European Central Bank 2017c) 
a QE-linked indicator, i.e., the time series of the purchases carried out by the Eurosystem within the APP, and both the time series of intra-financial and financial-real interactions. This analysis provides us with empirical evidence on the positive correlation between $\mathrm{QE}$ and both intra-financial assets (with a correlation coefficient equal to 0.60 ) and financial-real assets (with a correlation coefficient equal to 0.69).

\section{Conclusion}

In this paper, we have conducted an empirical exploratory analysis to study the implications of a specific case of unconventional monetary policy: ECB's QE. In particular, we aimed at investigating two main open issues. First, to what extent QE may generate net flows of additional resources to the real economy. Second, to what extent QE may alter the pattern of intra-financial exposures via loans and deposits, debt securities, and shares and other equity. Our empirical results constitute a contribution to the debate on the effects of unconventional monetary policy, as they reveal two main findings. First, since the implementation of QE, there has been an increase in financial system activities, via loans and deposits, debt securities, and shares and other equity. Second, this increase in the financial system interactions is mostly due to the increase in the intra-financial activity, rather than to the increase in the financial system activity addressed to the real economy. This fact is consistent with the process of progressive financialization of the economy, which has been experienced over the last decades. ${ }^{28}$ Indeed, the fact that a large fraction of financial system's assets is intra-financial, while only a minor share of the financial system activity is addressed to fund productive investment in the business sector is recognized as one of the key drivers of financialization (Turner 2017). This fact constitutes a particular concern in Europe, where the productive structure is mainly based on small and medium enterprises, which rely on the financial system, rather than on markets, to obtain funding. However, as in most serious debates, the truth may lie somewhere in the middle. In fact, since our paper, to the best of our knowledge, is the first to provide empirical evidence on the temporal relationship among the implementation of QE, the time evolution of multilayer macro-network's financial linkages, and the financialization in the euro area setting, some issues remain open and further research is needed to address them. For example, our data do not allow us to assess a causal relationship between the implementation of QE and the time evolution of intra-financial and financial-real activity. In this regard, our future research will focus, among other things, on addressing causality issues, identifying whether the scarce credit flow from the financial system to the real economy is due to the lack of bank credit supply or real economy credit demand, and exploring what would be the current role played by the financial system in the euro area in the absence of QE.

\footnotetext{
${ }^{28}$ The increase in the intra-financial system activity compared to the financial system's business addressed to fund new productive capital investment in the real economy is also consistent with the phenomenon identified by Allen and Santomero (2001) as the evolution of markets as "market for intermediaries rather than individuals or firms".
} 
Acknowledgements We are grateful to Joseph Stiglitz and Marco D'Errico for the insightful comments and discussions on an early stage of this research work. We also appreciated the helpful comments received at the 6th Lindau Meeting on Economic Sciences from Lars P. Hansen, Finn E. Kydland, Edward C. Prescott, Christopher A. Sims, Christopher A. Pissarides, and Martin Hellwig. Furthermore, we thank for comments and suggestions the participants in the 1st Annual Conference of the JRC Community of Practice in Financial Research in 2018, 17th International Conference CREDIT 2018, 24th International Conference on Computing in Economics and Finance 2018, NetSci2018 Conference, 2nd Conference on Financial Networks and Sustainability in 2018, 1st Change Finance Forum in 2017, 29th Annual EAEPE Conference in 2017, BigDataFinance Mid-Term meeting in 2017, and the 6th Lindau Nobel Laureate Meeting on Economic Sciences in 2017. We gratefully acknowledge the financial support from the BigDataFinance project that received funding from the European Union's Horizon 2020 research and innovation program under the Marie Sklodowska-Curie grant agreement No 675044.

Funding This work has been supported by the BigDataFinance project that received funding from the European Union's Horizon 2020 research and innovation program under the Marie Sklodowska-Curie grant agreement No 675044. Open access funding has been provided by University of Zurich.

\section{Compliance with Ethical Standards}

Conflict of interests The authors declare that they have no conflict of interest.

Open Access This article is licensed under a Creative Commons Attribution 4.0 International License, which permits use, sharing, adaptation, distribution and reproduction in any medium or format, as long as you give appropriate credit to the original author(s) and the source, provide a link to the Creative Commons licence, and indicate if changes were made. The images or other third party material in this article are included in the article's Creative Commons licence, unless indicated otherwise in a credit line to the material. If material is not included in the article's Creative Commons licence and your intended use is not permitted by statutory regulation or exceeds the permitted use, you will need to obtain permission directly from the copyright holder. To view a copy of this licence, visit http://creativecommonshorg/licenses/by/4.0/.

\section{References}

Acharya VV, Imbierowicz B, Steffen S, Teichmann D (2017) Does the lack of financial stability impair the transmission of monetary policy? SSRN Working Paper Series

Acharya VV, Eisert T, Eufinger C, Hirsch CW (2018) Whatever it takes: the real effects of unconventional monetary policy. Available at SSRN 2740338

Agarwal S, Chomsisengphet S, Mahoney N, Stroebel J (2017) Do banks pass through credit expansions to consumers who want to borrow? Q J Econ 133(1):129-190

Akerlof GA, Shiller RJ (2015) Phishing for phools: the economics of manipulation and deception. Princeton University Press, Princeton

Allahrakha M, Glasserman P, Young HP et al (2015) Systemic importance indicators for 33 US bank holding companies: an overview of recent data. Office of Financial Research

Allen F, Gale D (2000) Financial contagion. J Political Econ 108(1):1-33

Allen F, Santomero AM (2001) What do financial intermediaries do? J Bank Financ 25(2):271-294

Allen F, Babus A, Carletti E (2012) Asset commonality, debt maturity and systemic risk. J Financ Econ 104(3):519-534

Altavilla C, Giannone D, Lenza M (2014) The financial and macroeconomic effects of OMT announcements. Centre for Economic Policy Research (CEPR)

Assa J (2012) Financialization and its consequences: the OECD experience. Finance Research 1(1):35-39

Bank for International Settlements (BIS) (2008) Semiannual survey

Bank for International Settlements (BIS) (2013) Statistical release: OTC derivatives at the end of decemeber 2012

Bank of Latvia (2018) Non-MMF investment funds. https://www.bank.lv/en/your-profile/media/ press-releases/555-statistics/statistics-terms/9348-non-mmf-investment-funds 
Bardoscia M, Battiston S, Caccioli F, Caldarelli G (2015) Debtrank: a microscopic foundation for shock propagation. PloS One 10(6):e0130406

Bardoscia M, Battiston S, Caccioli F, Caldarelli G (2017) Pathways towards instability in financial networks. Nat Commun 8:14416

Barrat A, Barthélemy M, Vespignani A (2004) Weighted evolving networks: coupling topology and weight dynamics. Phys Rev Lett 92(22):228701

Battiston S, Gatti DD, Gallegati M, Greenwald B, Stiglitz JE (2012a) Liaisons dangereuses: increasing connectivity, risk sharing, and systemic risk. J Econ Dyn Control 36(8):1121-1141

Battiston S, Puliga M, Kaushik R, Tasca P, Caldarelli G (2012b) Debtrank: Too central to fail? financial networks, the fed and systemic risk. Sci Rep 2:541

Battiston S, Caldarelli G, D'Errico M (2016a) The financial system as a nexus of interconnected networks. In: Interconnected networks. Springer, pp 195-229

Battiston S, Caldarelli G, D'Errico M, Gurciullo S (2016b) Leveraging the network: a stress-test framework based on DebtRank. Statistics \& Risk Modeling 33(3-4):117-138

Borio C, Zabai A (2018) 20. Unconventional monetary policies: a re-appraisal. Research Handbook on Central Banking p 398

Castiglionesi F, Navarro N (2008) Optimal fragile financial networks. EFA 2008 Athens Meetings Paper

Castrén O, Rancan M (2014) Macro-networks: an application to euro area financial accounts. J Bank Financ 46:43-58

Chakraborty I, Goldstein I (2017) Monetary stimulus and bank lending. Finance Down Under 2017 Building on the Best from the Cellars of Finance

Crosignani M, Carpinelli L (2016) The effect of central bank liquidity injections on bank credit supply. New York University, Working Paper

Daetz SL, Subrahmanyam MG, Tang DY, Wang SQ (2016) Did ECB liquidity injections help the real economy?. New York University, New York

D'Errico M, Roukny T (2017) Compressing over-the-counter markets. arXiv: 170507155

D'Errico M, Battiston S, Peltonen T, Scheicher M (2018) How does risk flow in the credit default swap market? Journal of Financial Stability 35:53-74

Di Maggio M, Kermani A, Palmer C (2016) How quantitative easing works: evidence on the refinancing channel. Tech. rep., National Bureau of Economic Research

Dudley WC, Hubbard RG (2004) How capital markets enhance economic performance and facilitate job creation. Global Markets Institute. Goldman Sachs

Dufrénot G, Mignon V, Peguin-Feissolle A (2009) Testing the finance-growth link: is there a difference between developed and developing countries? Economics Bulletin

Eisenberg L, Noe TH (2001) Systemic risk in financial systems. Manag Sci 47(2):236-249

Eisenschmidt J, Kedan D, Schmitz M, Adalid R, Papsdorf P (2017) The Eurosystem's asset purchase programme and TARGET balances. ECB Occasional Paper (196)

Elsinger H, Lehar A, Summer M (2006) Risk assessment for banking systems. Manage Sci 52(9):13011314

Epstein G (2001) Financialization, rentier interests, and central bank policy. Manuscript, Department of Economics, University of Massachusetts Amherst, MA, December

European Central Bank (2006) List of Monetary Financial Institutions in the Acceding Countries. https:// www.ecb.europa.eu/stats/pdf/money/mfi/mfiac-aug2006.pdf?afaefece6d8850a234d77f55c94c892c

European Central Bank (2017a) All glossary entries. https://www.ecb.europa.eu/home/glossary/html/ glossi.en.html

European Central Bank (2017b) Asset purchase programmes. http://www.ecb.europa.eu/mopo/implement/ omt/html/index.en.html

European Central Bank (2017c) ECB Statistical Data Warehouse. http://sdw.ecb.europa.eu/

European Central Bank (2017d) How quantitative easing works. https://www.ecb.europa.eu/explainers/ show-me/html/app_infographic.en.html

European Central Bank (2015) Press release - ECB announces expanded asset purchase programme. https://www.ecb.europa.eu/press/pr/date/2015/html/pr150122_1.en.html

European Commission (2017) Institutional sectors. http:/ec.europa.eu/eurostat/web/sector-accounts/ concepts/institutional-sectors

Favara G (2003) An empirical reassessment of the relationship between finance and growth. IMF working paper

Freeman LC (1978) Centrality in social networks conceptual clarification. Social Networks 1(3):215-239 
Freeman RB (2010) It's financialization! Int Labour Rev 149(2):163-183

Gambacorta L, Hofmann B, Peersman G (2014) The effectiveness of unconventional monetary policy at the zero lower bound: a cross-country analysis. J Money Credit Bank 46(4):615-642

Gambetti L, Musso A (2017) The macroeconomic impact of the ECB's expanded asset purchase programme (APP). ECB Working Paper

Gelb AH (1989) Financial policies, growth, and efficiency, vol 202. World Bank Publications

Goldsmith RW (1975) The quantitative international comparison of financial structure and development. J Econ Hist 35(1):216-237

Greenwood R, Scharfstein D (2013) The growth of finance. J Econ Perspect 27(2):3-28

Grosse-Rueschkamp B, Steffen S, Streitz D (2017) Cutting Out the middleman: the ECB as corporate bond investor. Available at SSRN

Haldane A, Brennan S, Madouros V (2010) What is the contribution of the financial sector: miracle or mirage? The Future of Finance 87

International Monetary Fund (IMF) (2006) IMF global financial stability report: market developments and issues

Jacobs M, Mazzucato M (2016) Rethinking capitalism: economics and policy for sustainable and inclusive growth. John Wiley \& Sons, New York

Jordà Ò, Schularick M, Taylor AM (2016) The great mortgaging: housing finance, crises and business cycles. Econ Policy 31(85):107-152

Joyce M, Lasaosa A, Stevens I, Tong M et al (2011) The financial market impact of quantitative easing in the United Kingdom. Int J Cent Bank 7(3):113-161

Junker BH, Schreiber F (2011) Analysis of biological networks, vol 2. John Wiley \& Sons, New York

Kaushik R, Battiston S (2013) Credit default swaps drawup networks: too interconnected to be stable? PloS One 8(7):e61815

Kedrosky P, Stangler D (2011) Financialization and its entrepreneurial consequences. Ewing Marion Kauffman Foundation Research Paper

King RG, Levine R (1992) Financial indicators and growth in a cross section of countries, vol 819. World Bank Publications

King RG, Levine R (1993a) Finance and growth: Schumpeter might be right. Q J Econ 108(3):717-737

King RG, Levine R (1993b) Finance, entrepreneurship and growth. J Monet Econ 32(3):513-542

Krippner GR (2005) The financialization of the american economy. Socio-Econ Rev 3(2):173-208

Krishnamurthy A, Nagel S, Vissing-Jorgensen A (2017) ECB Policies involving government bond purchases: impact and channels. Eur Finan Rev 22(1):1-44

Lima L, Vasconcelos CF, Simão J, de Mendonça HF (2016) The quantitative easing effect on the stock market of the USA, the UK and japan: an ARDL approach for the crisis period. J Econ Stud 43(6):1006-1021

McKinnon RI (2010) Money and capital in economic development. Brookings Institution Press

Neal CR (1990) Macrofinancial indicators for 117 developing and industrial countries: background paper for the 1989 world development report, vol 58. World Bank Publications

OECD (2017) Government at a glance 2017. OECD

Oliver Wyman (2010) The Future of Banking

Opsahl T, Agneessens F, Skvoretz J (2010) Node centrality in weighted networks: generalizing degree and shortest paths. Social networks 32(3):245-251

Palley TI (2013) Financialization: what it is and why it matters. In: Financialization. Springer, pp 17-40

Perillo C, Battiston S (2017) Real implications of quantitative easing in the euro area: a complex-network perspective. In: International workshop on complex networks and their applications. Springer, pp 1162-1173

Perillo C, Battiston S (2018) A multiplex financial network approach to policy evaluation: the case of euro area quantitative easing. Appl Netw Sci 3(1):49

Philippon T, Reshef A (2012) Wages and human capital in the US finance industry: 1909-2006. Q J Econ 127(4):1551-1609

Rajan RG, Zingales L (2004) Saving capitalism from the capitalists: unleashing the power of financial markets to create wealth and spread opportunity. Princeton University Press, Princeton

Reinhart MC, Rogoff MK (2013) Financial and sovereign debt crises: some lessons learned and those forgotten. 13-266, International Monetary Fund

Rodnyansky A, Darmouni OM (2017) The effects of quantitative easing on bank lending behavior. Rev Financ Stud 30(11):3858-3887 
Roukny T, Bersini H, Pirotte H, Caldarelli G, Battiston S (2013) Default cascades in complex networks: topology and systemic risk. Scientific reports 3

Roukny T, Battiston s, Stiglitz JE (2016), Interconnectedness as a source of uncertainty in systemic risk. Journal of Financial Stability

Smaghi LB (2009) Conventional and unconventional monetary policy. Speech at the Center for Monetary and Banking Studies Geneva 28

Stiglitz JE (2010) Contagion, liberalization, and the optimal structure of globalization. Journal of Globalization and Development 1(2):1-47

Stockhammer E (2004) Financialisation and the slowdown of accumulation. Camb J Econ 28(5):719-741

Stolbova V, Monasterolo I, Battiston S (2018) A financial macro-network approach to climate policy evaluation. Ecol Econ 149:239-253. Elsevier

Szczerbowicz U et al (2015) The ECB unconventional monetary policies: have they lowered market borrowing costs for banks and governments? Int J Cent Bank 11(4):91-127

Turner A (2017) Between debt and the devil: money, credit, and fixing global finance. Princeton University Press, Princeton

Visentin G, Battiston S, D'Errico M (2016) Rethinking financial contagion. Available at SSRN 2831143

Wagner W (2010) Diversification at financial institutions and systemic crises. J Financ Intermed 19(3):373-386

Publisher's note Springer Nature remains neutral with regard to jurisdictional claims in published maps and institutional affiliations.

\section{Affiliations}

\section{Chiara Perillo $^{1}{ }^{\mathbb{D}}$. Stefano Battiston ${ }^{1}$}

Stefano Battiston

stefano.battiston@uzh.ch

1 FINEXUS Center for Financial Networks and Sustainability, Department of Banking and Finance, University of Zurich, Zurich, Switzerland 